\title{
Secretory granule protein chromogranin B (CHGB) forms an anion channel in membranes
}

\author{
Gaya P Yadav , Hui Zheng ${ }^{2}$, Qing Yang ${ }^{3}$, Lauren G Douma ${ }^{4}$, Linda B Bloom4, Qiu-Xing Jiang ${ }^{10}$
}

\begin{abstract}
Regulated secretion is an intracellular pathway that is highly conserved from protists to humans. Granin family proteins were proposed to participate in the biogenesis, maturation and release of secretory granules in this pathway. However, the exact molecular mechanisms underlying the intracellular functions of the granin family proteins remain unclear. Here, we show that chromogranin B (CHGB), a secretory granule protein, inserts itself into membrane and forms a chloride-conducting channel. CHGB interacts strongly with phospholipid membranes through two amphipathic $\alpha$ helices. At a high local concentration, CHGB insertion in membrane causes significant bilayer remodeling, producing protein-coated nanoparticles and nanotubules. Fast kinetics and high cooperativity for anion efflux from CHGB vesicles suggest that CHGB tetramerizes to form a functional channel with a single-channel conductance of $\sim 125 \mathrm{pS}\left(150 / 150 \mathrm{mM} \mathrm{Cl}^{-}\right)$. The CHGB channel is sensitive to an anion channel blocker and exhibits higher anion selectivity than the other six known families of $\mathrm{Cl}^{-}$channels. Our data suggest that the CHGB subfamily of granin proteins forms a new family of organelle chloride channels.
\end{abstract}

Dol 10.26508/Isa.201800139 | Received 26 July 2018 | Revised 29 August 2018 | Accepted 11 September 2018 | Published online 24 September 2018

\section{Introduction}

Cells rely on secretory pathways to send out specific bioactive molecules to their surroundings (Grimes \& Kelly, 1992). Both constitutive and regulated secretory pathways have been studied extensively since early EM observations of intracellular vesicular trafficking. Many molecular players in these pathways are known. Conserved mechanisms for vesicle targeting and membrane fusion are established (Farquhar \& Wellings, 1957; Jamieson \& Palade, 1964; Rothman, 1994; Salama \& Schekman, 1995; Rizo \& Xu, 2015). The three key steps of regulated secretion are granule biogenesis at the TGN, granule maturation through fusion, sorting and membrane shedding, and exocytotic release of mature granules (Hosaka \& Watanabe, 2010). Maturation of nascent immature secretory granules (ISGS) into dense-core granules (DCGs) is accompanied by $\mathrm{H}^{+}$
-ATPase-driven acidification and resorting of granule proteins and cargos (Johnson \& Scarpa, 1976; Johnson et al, 1982).

Granin family proteins are by default granule proteins that chaperone other secretory molecules through regulated secretion (Hosaka \& Watanabe, 2010; Bartolomucci et al, 2011). They have both intracellular and extracellular functions. Chromogranins (CHGs) are believed to function in all three steps of the regulated secretory pathway. It was proposed that CHGs interact with cargos and serve as a low-affinity, high-capacity $\mathrm{Ca}^{2+}$ reserve. Their extracellular functions are executed by CHG-derived peptides that are associated with various human diseases (Bartolomucci et al, 2011). However, the molecular mechanisms for all CHGs' intracellular functions remain to be elucidated.

Members of the granin superfamily (Bartolomucci et al, 2011) share low amino acid sequence similarity (Montero-Hadjadje et al, 2008) and are clustered into phylogenetic subfamilies. Granin proteins of distinct subfamilies usually coexist in secretory granules and were hypothesized to work with different partners (Bartolomucci et al, 2011). Native chromogranin B (CHGB) forms high-order aggregates at low $\mathrm{pH}$ and with millimolar $\mathrm{Ca}^{2+}$ (Yoo, 1995a, 1995b). It is genetically associated with type 2 diabetes, neurodegeneration, and psychiatric disorders (Gros-Louis et al, 2009; Davenport et al, 2010; Dominguez et al, 2012; Fuchsberger et al, 2016). It was proposed to participate in forming TGN proteinaceous aggregates and driving granule biogenesis in certain cell types (Tooze, 1998; Takeuchi \& Hosaka, 2008; Diaz-Vera et al, 2012). Studies of CHGB-null mice by two groups reported cell-specific variations regarding $\mathrm{CHGB}^{\prime}$ s role in granule biogenesis, but similar roles in cargo maturation or monoamine loading into granules (Zhang et al, 2009; Diaz-Vera et al, 2010; Obermuller et al, 2010; Zhang et al, 2014). Even though CHGB has been prepared in heat-stable soluble fractions as protein complexes, partially purified native CHGB interacted quite strongly with lipid vesicles (Yoo, 1995b). A "tightly membrane-associated form" of CHGB was observed on the surface of PC-12 cells after exocytotic release of secretory granules (Pimplikar \& Huttner, 1992). CHGB thus has dual states-outside or inside membranes. However, a mechanistic view on CHGB's functions in these two states is still unavailable.

\footnotetext{
'Department of Microbiology and Cell Science, University of Florida, Gainesville, FL, USA ${ }^{2}$ Department of Physiology, University of Texas Southwestern Medical Center at Dallas, Dallas, TX, USA ${ }^{3}$ Crop Designing Center, Henan Academy of Agricultural Sciences, Zhengzhou, PR China ${ }^{4}$ Department of Biochemistry and Molecular Biology, University of Florida, Gainesville, FL, USA
}

Correspondence: qxjiang@ufl.edu 
In this work, we investigate the functional properties of CHGB proteins in different membrane systems and demonstrate that CHGB inserts into membrane and by itself suffices to form an unconventional chloride channel in vitro. A companion article will study the CHGB channel function in neuroendocrine cells.

\section{Results}

\section{CHGB inserts into membranes and induces nanoparticles and nanotubules from bilayers}

To study CHGB function, recombinant murine CHGB was purified from sf9 cells (Fig S1A). During biochemical preparation, Triton $\mathrm{X}$-100-like detergents were needed to keep CHGB soluble. In sizeexclusion chromatography (SEC), purified CHGB was eluted as a single, symmetric peak (Fig 1A) with an apparent size equivalent to an $\sim 300$ kD globular protein. Because of posttranslational modifications, a high content of charged residues, or possibly detergentbinding, the recombinant CHGB ran at $\sim 86 \mathrm{kD}$ in a reducing SDSPAGE gel (Fig 1B and C), which is larger than the $78 \mathrm{kD}$ calculated from its sequence, behaving similarly to mature human $\mathrm{CHGB}$ (Pimplikar \& Huttner, 1992). Because of the detergent micelle ( 100 $\mathrm{kD})$, the $\mathrm{CHGB}$ in detergents are likely a dimer, instead of a trimer. The detergent-solubilized CHGB treated with a bifunctional crosslinker, 4-(N-maleimidomethyl) cyclohexane-1-carboxylic acid 3-sulfo$\mathrm{N}$-hydroxysuccinimide ester (sulfo-SMCC), showed cross-linked dimers, trimers, tetramers, and high-order oligomers $\left(U_{2}, U_{3}, U_{4}\right.$, and $U_{n}$ in Fig $1 \mathrm{~B}$ ), indicating a dynamic equilibrium between dimers and oligomers $\left(U_{n}, n \geq 3\right)$ and the dominance of dimers in detergents. Consistently, small amounts of CHGB oligomers were observed in an earlier SEC step during purification (Fig S2A).

Calcium binding is a biochemical hallmark of CHGB because of a high content of negatively charged residues. We examined calciuminduced CHGB aggregates by light-scattering and negative-stain EM
(Fig S2B-F). Fitting of light-scattering data with a Hill equation yielded an apparent $k_{D} \sim 0.25 \mathrm{mM}$ for $\mathrm{Ca}^{2+}$, and a Hill coefficient of $\sim 2.0$ (Fig S2B), agreeing with CHGB's low affinity and high capacity for $\mathrm{Ca}^{2+}$ (Yoo \& Lewis, 1996). EM examination found that without $\mathrm{Ca}^{2+} \mathrm{CHGB}$ in detergents was monodispersed (Fig S2C). The size and amount of $\mathrm{Ca}^{2+}$ -induced aggregates increased significantly when $\left[\mathrm{Ca}^{2+}\right]$ rose from 0.2 to $5.0 \mathrm{mM}$ (Fig S2D-F).

To resolve the ambiguity between $\mathrm{CHGB}$ dimers and trimers in detergents, we performed single particle reconstruction. More than 5,400 particle images of negatively stained CHGB molecules (Fig S2G) were assembled for multi-variate statistical analysis (MSA). The eigenimages from MSA (top in Fig 1C) showed strong C2 symmetry. Angular reconstitution and 3D refinement yielded a negative-stain map at $\sim 30 \AA$ (Fig S2H). CHGB's small mass made it difficult to visualize under cryoEM. We used a Chemic (chemically functionalized carbon) method (Llaguno et al, 2014) to enhance cryoEM image contrast (Fig S2I). More than 24,000 cryoEM images of CHGB molecules were manually selected for analysis. Multi-rounds of $2 \mathrm{D}$ and 3D classification led to a homogenous set of $\sim 6,900$ particles and a 3D map at $\sim 10 \AA$ resolution (Fig 1D), estimated by the goldstandard Fourier shell correlation (0.143). The cryoEM map has C2 symmetry and an elongated shape, explaining its larger apparent size in SEC (Fig 1A). Its distinct features may correspond to the predicted helical and random-coil regions, and verify CHGB's dimeric nature in detergents (Fig $1 \mathrm{~A}$ and $\mathrm{C}$ ).

The surprising need of detergents for CHGB stability in solution intrigued us to study whether it directly interacts with membranes using a vesicle flotation assay (Zheng et al, 2011). After reconstitution with phospholipids (Lee et al, 2013), CHGB floated with vesicles from bottom to top in a three-step Ficoll 400 gradient (arrow in the top of Fig 1E). Quantification of the protein bands revealed that $>98 \%$ of $\mathrm{CHGB}$ protein was in membrane (Fig $1 \mathrm{E}$, bottom panel), suggesting that with sufficient membrane surfaces, CHGB prefers to be in the membrane-associated state.
A
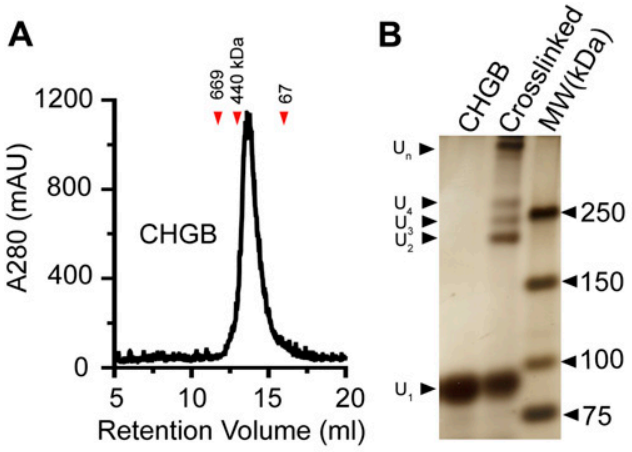

E

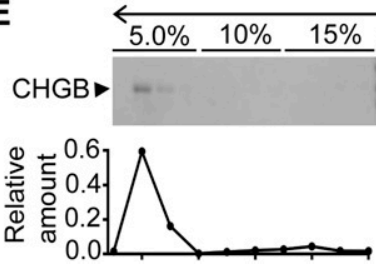

C

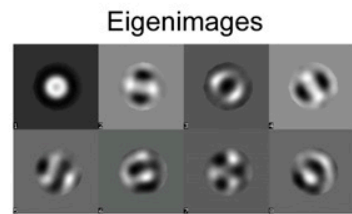

D

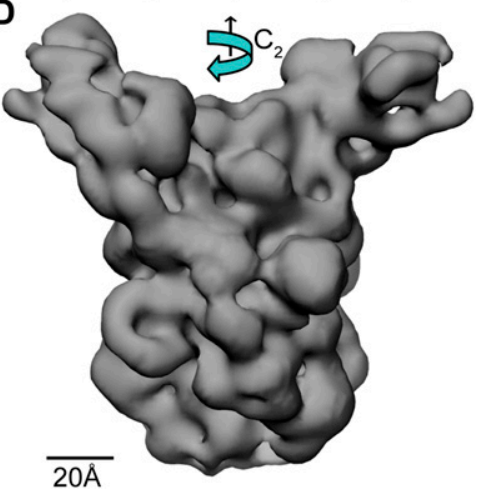

Figure 1. Strong interaction of CHGB and lipid membrane.

(A) SEC profile for purified CHGB. Red triangles indicate molecular weight markers. (B) Silver-stained SDS-PAGE gel of dimers $\left(U_{2}\right)$, trimers $\left(U_{3}\right)$, tetramers $\left(U_{4}\right)$, and high-order oligomers $\left(U_{n}\right)$ in CHGB treated with sulfoSMCC (middle). (C) First eight eigenimages from MSA of a negative-stain EM dataset show C2 symmetry. (D) A cryoEM map for CHGB dimer at $\sim 10 \AA$. (E) Top: SDS-PAGE of fractions from a vesicle floatation assay of CHGB in egg PC vesicles in a three-step Ficoll 400 gradient. The top arrow marks the vesicle floatation from bottom (15\%) to top (5\%). Bottom: quantified CHGB distribution from SDS-PAGE. The floatation experiments were repeated more than 20 times for different batches of CHGB vesicles. 
CHGB may cause significant membrane remodeling. To visualize the effects of CHGB-membrane interaction on the bilayer structure, we examined $\mathrm{CHGB}$ vesicles by negative-stain EM (Fig 2A-D). When CHGB:lipid molar ratio $(P L R) \geq 1: 1,000$, equivalent to $\sim 40$ CHGB dimers per 100-nm vesicle, 25-nm nanospheres appeared on vesicles (red arrowheads in Fig 2B). More CHGB led to $\sim 20$-nm-thick nanotubules capped with 25-nm-diameter hemi-nanospheres (Fig $2 \mathrm{C}$ and D). In some specimens, the nanospheres were severed into individual soluble nanoparticles (Fig 2C). These results reveal CHGB-induced remodeling of membranes when local PLR is high, a condition likely being satisfied at the TGN sites for granule biogenesis, which might contribute to the heat-stable or soluble fractions used in previously published studies (Benedum et al, 1986; Benedum et al, 1987). The nanotubules and nanospheres indicate strong positive curvature caused by CHGB. To avoid membrane remodeling, we intentionally limited the $P L R<1: 5,000$ in most vesicle-based assays.

Lipid membranes drive CHGB oligomerization. When purified, CHGB was first reconstituted into vesicles and then extracted with detergents plus $\sim 0.1 \mathrm{mg} / \mathrm{ml}$ lipids, $>70 \%$ of CHGB protein was eluted by SEC at a position equivalent to an $\sim 0.8$ MD globular protein, suggesting that lipids may stabilize a high-order oligomer. Because of the elongated shape of the cryoEM map (Fig 1D), biochemically cross-linked tetramers (Fig 1C) and the detergent micelles, the smallest lipid-stabilized oligomers may be a tetramer ( $\mathrm{U}_{4}$; Fig S2A). It may endow the function of CHGB in membrane.

CHGB is inserted in membrane. When CHGB vesicles were treated with trypsin, almost all full-length $\mathrm{CHGB}$ (Fig 2E) was digested after 50 min. With $\mathrm{Ca}^{2+}$-loaded CHGB vesicles (Fig S3A) and a $\mathrm{Ca}^{2+}$-sensitive dye, Indo-1, in the outside, we discovered that trypsin treatment did not break the membranes to cause any leak of $\mathrm{Ca}^{2+}$, meaning that trypsin did not penetrate into the interior of the vesicles (Fig S3D). The nearly complete digestion of CHGB in vesicles indicates that almost all full-length CHGB proteins were inserted into membranes from the outside of the vesicles. A stable fragment out of trypsinization was membraneprotected and was named the membrane-interacting fragment (MIF) of $\mathrm{CHGB}$ (Fig 2E). The asymmetric membrane insertion of $\mathrm{CHGB}$ is expected to introduce positive curvature into membranes (Fig 2F) and lead to the nanotubules and nanoparticles (Fig 2B-D).

\section{Amphipathic segments are responsible for strong CHGB-membrane interaction}

To examine the biophysical nature of $\mathrm{CHGB}$-induced membrane curvature, next, we tested whether CHGB causes membrane breakdown. A fluorescein-release assay was implemented (Mukherjee et al, 2014) to monitor the increase in fluorescence when the carboxy fluorescein was released and unquenched. For this assay, valinomycin, a $\mathrm{K}^{+}$carrier, in DMSO (dimethyl sulfoxide) was introduced to eliminate charge accumulation. Our data showed that CHGB vesicles did not leak the $10-\AA$ fluorophore (Fig 3A). When CHGB vesicles were loaded with $\mathrm{Ca}^{2+}$, Indo-1 in the outside detected no leak of $\mathrm{Ca}^{2+}$ (Figs 3B and S3A). As a positive control, purified type 1 inositol 3,4,5-trisphosphate $\left(\mathrm{IP}_{3}\right)$ receptors $\left(I_{3} R 1\right)$ in vesicles generated $I_{3}$-triggered $\mathrm{Ca}^{2+}$ release (Fig $\mathrm{S} 3 \mathrm{~B}$ ). The $\mathrm{CHGB}$ vesicles are thus very tight and the $\mathrm{CHGB}$ does not conduct $\mathrm{Ca}^{2+}$.

We then investigated if $\mathrm{CHGB}$ vesicles release $\mathrm{Cl}^{-}$by using a $\mathrm{Ag}$ / $\mathrm{AgCl}$ (silver/silver chloride) electrode to measure $\mathrm{Cl}^{-}$as described by Stockbridge et al (2013). CHGB vesicles containing $300 \mathrm{mM} \mathrm{KCl}$ were changed into a buffer with $300 \mathrm{mM} \mathrm{K}$-isethionate plus $0.2 \mathrm{mM}$ $\mathrm{KCl}$ before being added into a recording chamber (diagramed in Fig $\mathrm{S3C}$ ). Adding valinomycin initiated $\mathrm{a} \mathrm{Cl}^{-}$signal that was a result of anion release from vesicles (bottom trace in Fig 3C). Control vesicles without $\mathrm{CHGB}$ showed no signal (top trace in Fig 3C). These findings suggest that a significant fraction of $\mathrm{CHGB}$ vesicles released their
A

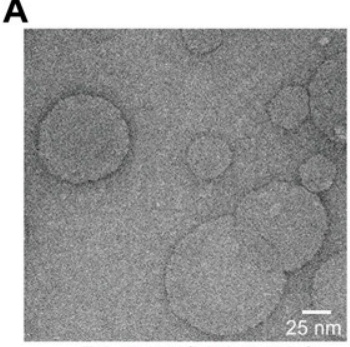

$P: L=0: 1$ (Molar ratio)

D

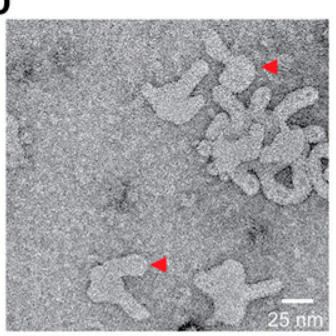

$P: L=1: 100$ (Molar ratio)
B

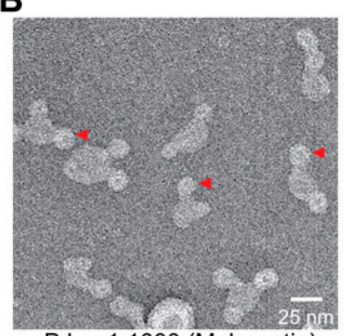

$P: L=1: 1000$ (Molar ratio)

E

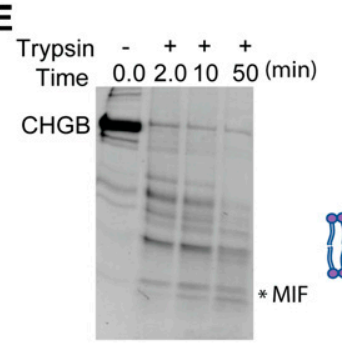

C

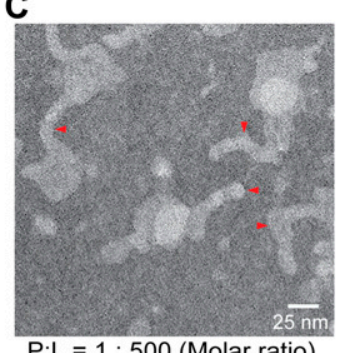

$\mathrm{P}: \mathrm{L}=1: 500$ (Molar ratio)

\section{$\mathbf{F}$}

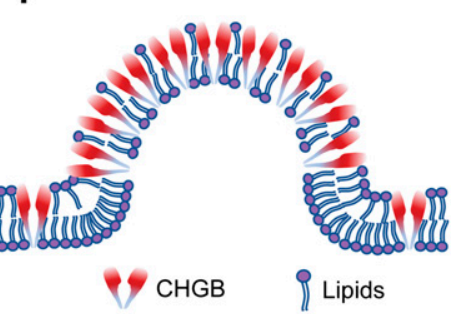

Figure 2. Membrane insertion of CHGB introduces positive curvature in bilayers.

Purified CHGB protein was reconstituted in lipid vesicles made of egg PC. Empty vesicles were prepared in the same way without CHGB. The vesicles were diluted by fivefold in a buffer containing $20 \mathrm{mM}$ Tris- $\mathrm{HCl}, \mathrm{pH} 7.4,100 \mathrm{mM} \mathrm{NaCl}, 1.0 \mathrm{mM}$ EDTA, and $2.0 \mathrm{mM}$ $\beta$-ME before being loaded on carbon-coated grids and stained with $2.0 \%$ PTA (phosphotungstic acid $/ \mathrm{KOH}, \mathrm{pH}$ 8.0). Typical images of empty vesicles (A), CHGB reconstituted vesicles at 1:10 protein/lipid weight ratio (1:1,000 in molar PLR or $\sim 40$ CHGB dimers per $100 \mathrm{~nm}$ vesicle) (B), CHGB reconstituted vesicles at 1:5 protein/lipid weight ratio (1:500 in molar PLR or $\sim 80$ CHGB dimers per $100 \mathrm{~nm}$ vesicle) (C), and CHGBreconstituted vesicles at 1:1 protein/lipid weight ratio (1:100 in molar PLR) (D) are shown. The experiments were repeated more than three times with very similar results. Budding compartments with positive curvature are marked with red arrowheads in (B-D). In (B), the nanospheres are marked at the tops of the nanotubules. Scale bars in A-D are all $25 \mathrm{~nm}$. (E) $10 \mu \mathrm{g}$ CHGB in egg PC vesicles treated with trypsin at RT. PMSF was used to stop the reaction. Samples collected at various time points were separated in a 4-20\% SDS-PAGE gel. The stable short fragment at 20 kD was collected for mass spectrometry analysis (marked as MIF), which is named as CHGB-MIF in Fig 3D-F. (F) Model for insertion of CHGB in membranes to cause positive curvature. 
A

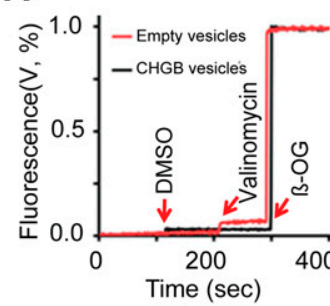

$\mathbf{D}_{-20}$
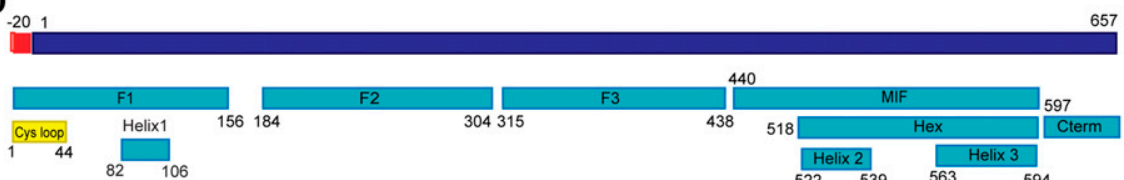

E

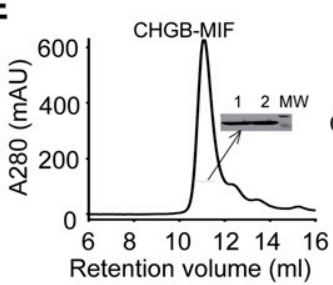

H

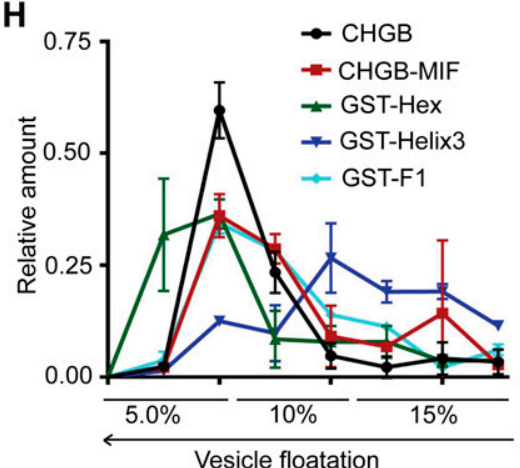

B

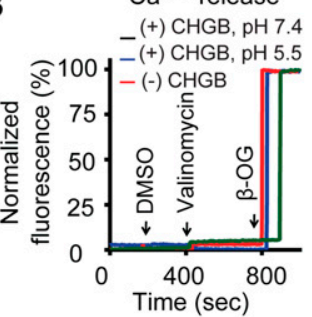

C

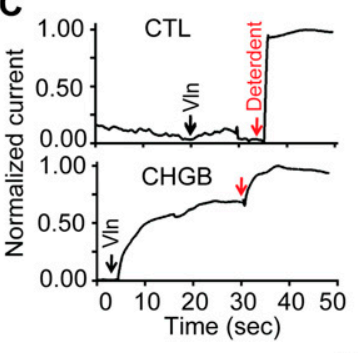

Figure 3. Mapping amphipathic helical segments for CHGB insertion in membrane.

(A) $\mathrm{CHGB}$ vesicles have no membrane cracks. CHGB vesicles loaded with $1.0 \mu \mathrm{M}$ carboxy fluorescein were treated with $1.0 \mu \mathrm{LMSO}, 1.0 \mu \mathrm{M}$ valinomycin, and finally with $5.0 \mathrm{mM} \beta-\mathrm{OG}$ to disrupt vesicles. (B) $\mathrm{CHGB}$ vesicles leak no $\mathrm{Ca}^{2+}$ at $\mathrm{pH} 7.4$ or 5.5. Vesicles loaded with $1.0 \mathrm{mM} \mathrm{CaCl}_{2}$ were treated with $1.0 \mu \mathrm{LMSO}, 1.0 \mu \mathrm{M}$ valinomycin, and finally with $5.0 \mathrm{mM} \beta$-OG. (C) $\mathrm{Cl}^{-}$ release from vesicles recorded with a $\mathrm{Ag} / \mathrm{AgCl}$ electrode. $300 \mathrm{mM} \mathrm{KCl}$ inside vesicles; $300 \mathrm{mM} \mathrm{K}$ isethionate and $0.2 \mathrm{mM} \mathrm{KCl}, 10 \mathrm{mM}$ Hepes pH 7.4 outside. $0.25 \mu \mathrm{M}$ valinomycin started the release. At the end $10 \mathrm{mM} \beta$-OG was added to release all $\mathrm{Cl}^{-}$. A typical trace out of three (bottom) was shown. Control vesicles (top panel) did not show valinomycin-triggered response. The recordings were normalized to the $\beta-O G$ signal. (D) A diagram of CHGB and different fragments. (E) SEC of CHGB-MIF in a Superdex 200 column. The inset is SDS-PAGE of two peak fractions. (F) Vesicle floatation assay for CHGB-MIF, GST-F1, and GST. (G, H) Distribution of $\mathrm{CHGB}$ and its fragments from vesicle floatation assays as in (F) and Fig S3E. Those staying at the bottom in (G) and those floating in (H). (I) A helical model for helix 1 with its hydrophobic residues in yellow. It was energetically optimized in Coot and presented in PyMol. (J) Structural model for helix 3.

internal $\mathrm{Cl}^{-}$. The need of valinomycin in these experiments suggested that the $\mathrm{CHGB}$ does not conduct $\mathrm{K}^{+}$significantly.

Chloride release from $\mathrm{CHGB}$ vesicles suggests that $\mathrm{CHGB}$ in membrane forms an anion conductance, either a transporter or an anion channel. It therefore must have a membrane-spanning domain. MIF revealed by the trypsinization experiment probably contributes to the transmembrane domain. Mass spectrometry and $\mathrm{N}$-terminal sequencing of MIF (Figs 2E and 3D) identified it as CHGB 440-597, which is named as CHGB-MIF. Secondary structure analysis of CHGB-MIF revealed a shorter segment (Hex, CHGB 518-597) containing two $\alpha$-helices interspaced by a short random-coil loop (Fig 3D and online servers detailed in Fig S4C). Vesicle flotation assays showed that recombinant CHGB-MIF alone interacts with membranes (Fig $3 \mathrm{E}$ and F), confirming that it is indeed a major contributor to CHGB-membrane interaction (Figs $1 \mathrm{E}$ and $2 \mathrm{~F}$ ).

Systematic mapping of MIFs identified two amphipathic $\alpha$-helices in CHGB (helices 1 and 3 in Figs 3D and S4A-G). Based on secondary structure prediction and the $\mathrm{CHGB}$ post-processing peptides, we purified multiple short segments of $\mathrm{CHGB}$, alone or as GST-fusion proteins, and reconstituted them for vesicle floatation (Figs 3D, F-H, and S3E). These short segments were all prepared as stable and monodisperse proteins without aggregation. As a positive control, $\mathrm{His}_{6}$-tagged MIF floated well (Fig $3 \mathrm{E}$ and F) because it was well protected by membrane (Fig 2E). Soluble GST alone failed to float (Fig 3F). Except helix 3, all fragments (Fig 3G and $\mathrm{H}$ ) fell into two groups: those floating and those sinking (Fig $3 \mathrm{G}$ versus $\mathrm{H}$; Fig S3E). GST-Helix 3, containing an amphipathic helix, was distributed between the two (Fig $3 \mathrm{H}$ ). The $\mathrm{N}$-terminal fragment F1 (Fig 3D and $\mathrm{H}$ ) contains the Cys-loop, which is a soluble sorting signal for granule biogenesis (Cys-loop Fig 3G), and a long amphipathic helix (helix 1, Figs 31 and S4A, B, and E). A structural model of helix 1 in Fig 31 shows its extensive hydrophobic surface (yellow; 36 A long). Not protected from trypsinization of CHGB in egg PC vesicles, helix 1 probably lies on the water membrane surface, instead of penetrating deeply into the membrane. Helices 2 and 3 (Figs 3) and S4C, D, F, and G) are well conserved within the CHGB subfamily (Fig S4C and D) and have weak and strong hydrophobic moments, respectively (Fig S4F and G). Helix 2 is thus hydrophilic 
and helix 3 amphipathic. Structural modeling of helix 3 (Fig 3J) revealed a hydrophobic surface (yellow) that is $>30 \AA$ in length, sufficient to span a typical bilayer membrane. Possible cooperativity between helices 2 and 3 within the Hex segment (Fig 3D) or between the Hex fragment and helix 1 may contribute to the "tightly membrane-associated form" of CHGB (Pimplikar \& Huttner, 1992).

\section{CHGB alone suffices to form an anion-selective channel}

To distinguish whether CHGB forms a transporter or a channel (Fig 3C), we first tested if it is feasible to record its activity in planar lipid bilayers (Lee et al, 2013). The membrane-remodeling property of CHGB made it difficult to record from many CHGB molecules. Instead, when diluted $\mathrm{CHGB}$ vesicles of low PLR $(\leq 1: 5,000)$ were fused into planar lipid bilayers in the presence of $0.5 \mathrm{mM} \mathrm{CaCl}_{2}$, we observed multiple channel events (Fig 4A). Under an asymmetrical $\mathrm{Cl}^{-}$ condition (42/166 mM), a significant inward current was recorded at $0 \mathrm{mV}$. The current was $\sim \mathrm{pA}$ at $30 \mathrm{mV}$ (red trace in Fig 4A), suggesting a reversal potential of $\sim+30 \mathrm{mV}$. The ionic conditions (cis/trans) defined the Nernst potentials for $\mathrm{Na}^{+}(173 / 167 \mathrm{mM}), \mathrm{Cl}^{-}(42 / 166 \mathrm{mM}$; including a small amount of $\left.\mathrm{F}^{-}\right), \mathrm{MES}^{-}(10 / 10 \mathrm{mM})$, and $\mathrm{Ca}^{2+}(0.5 /$ $0.001 \mathrm{mM}$; considering a trace amount of $\sim 1.0 \mu \mathrm{M} \mathrm{Ca}^{2+}$ in MilliQ water) to be $0.4,34.4,0$, and $315 \mathrm{mV}$, respectively. The average current versus potential plot (Fig S5C) suggested a reversal potential of $+30.5 \mathrm{mV}$. Linear fitting of the relation between single-channel currents and transmembrane potential revealed a singlechannel conductance of $\sim 140$ pS and a reversal potential of $29.9 \pm$ $2.7 \mathrm{mV}$ (red line in Fig 4B). The measured reversal potentials are close to the Nernst potential of $\mathrm{Cl}^{-}$. Under the assumption of zero conduction for $\mathrm{MES}^{-}$and $\mathrm{Ca}^{2+}$, the estimated permeation ratio between $\mathrm{Na}^{+}$and $\mathrm{Cl}^{-}\left(P_{\mathrm{Na}} / P_{\mathrm{Cl}}\right)$ is $\sim$ : 12.6, suggesting that the channel favors $\mathrm{Cl}^{-}$ over $\mathrm{Na}^{+}$significantly. The trace conduction of $\mathrm{MES}^{-}$and $\mathrm{Ca}^{2+}$ might
A

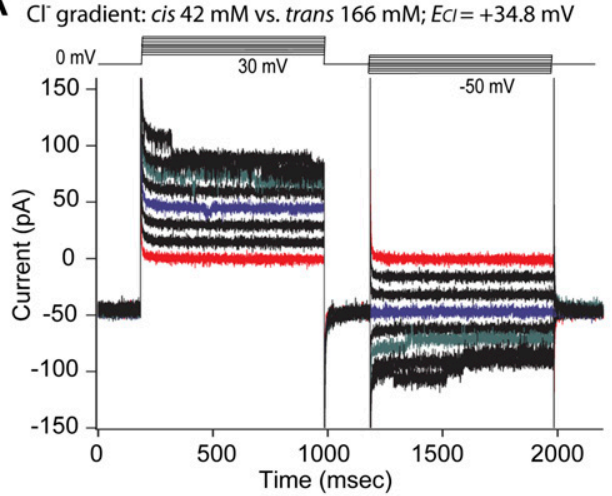

C cis: $135 \mathrm{mM} \mathrm{NaF}, 15 \mathrm{mM} \mathrm{NaCl}$; trans: $150 \mathrm{mM} \mathrm{NaCl}$

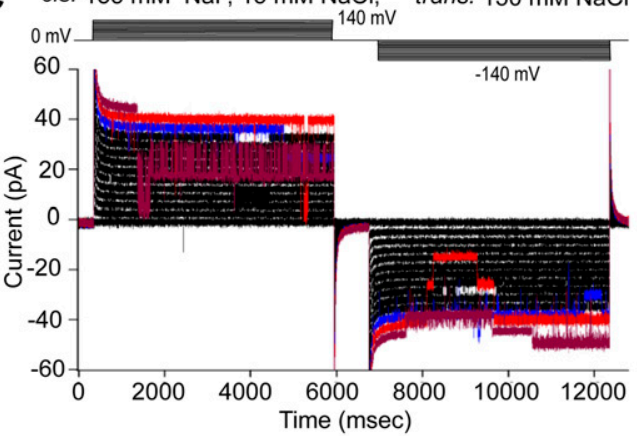

E

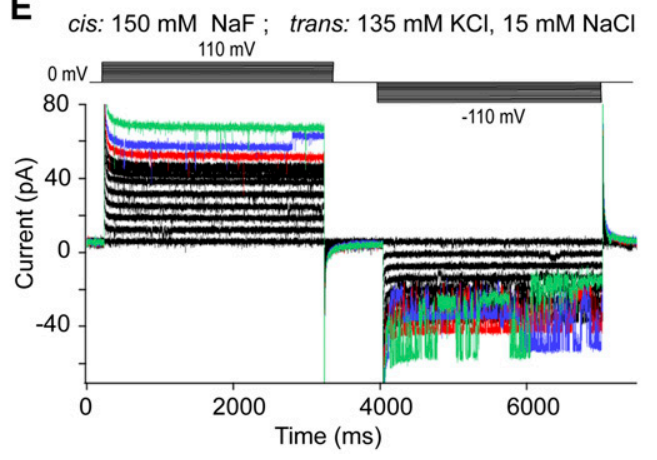

B

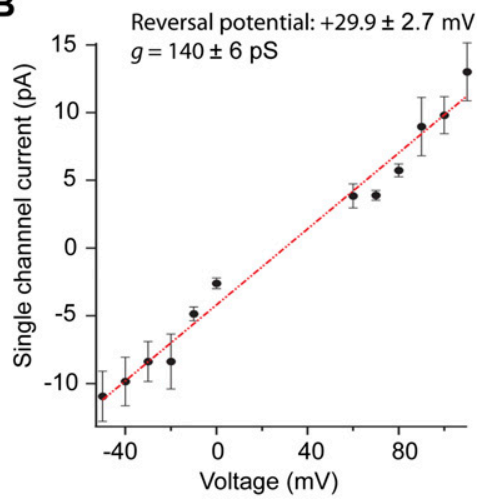

D

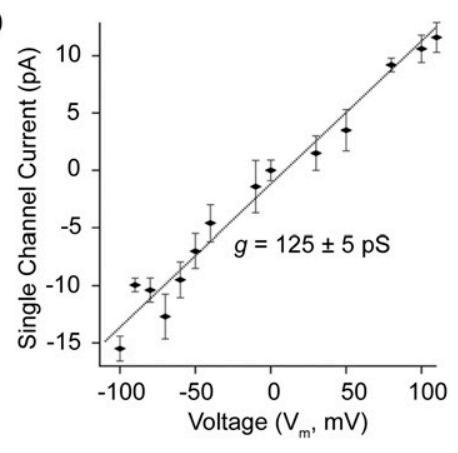

$\mathbf{F}$

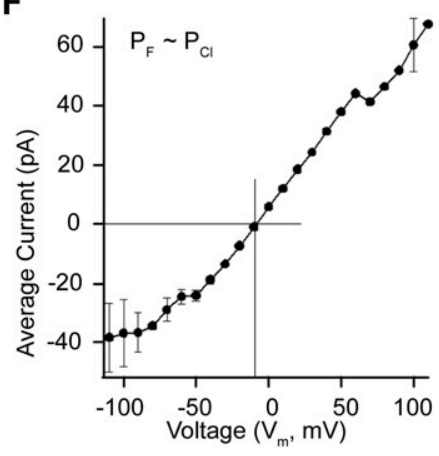

Figure 4. CHGB forms a chloride channel in membrane.

(A) Electrical recordings from multiple channels in a planar lipid bilayer. Solutions were cis: $30 \mathrm{mM} \mathrm{NaCl}$, $130 \mathrm{mM}$ Na-isethionate; $1.5 \mathrm{mM} \mathrm{NaF}, 0.5 \mathrm{mM} \mathrm{CaCl}_{2}$, $10 \mathrm{mM}$ MES-Na/HCl $\left(9.4 \mathrm{mM} \mathrm{Cl}^{-}\right), \mathrm{pH}$ 5.5; and trans: $157 \mathrm{mM} \mathrm{NaCl}, 10 \mathrm{mM}$ MES- $\mathrm{Na} / \mathrm{HCl}\left(9.4 \mathrm{mM} \mathrm{Cl}^{-}\right.$), pH 5.5. Holding potential: $0 \mathrm{mV}$; pulses in $10 \mathrm{mV}$ steps from 30 to $110 \mathrm{mV}$ and from 30 to $-50 \mathrm{mV}$ in two epochs, respectively. The Nernst potential for $\mathrm{Cl}^{-}(41.9 \mathrm{mM} /$ $\left.166.4 \mathrm{mM} ; E_{C l}\right)$ is $34.4 \mathrm{mV}$. At $0 \mathrm{mV}$, the current is -50 pA. (B) Single-channel currents versus transmembrane voltage $\left(V_{m}\right)$ from three different membranes in the same ionic conditions as in panel A. Error bars: SD from 3 to 10 histogram-based measurements of singlechannel currents under each Vm. Fitting of the data with a linear function (dotted line) yielded a singlechannel conductance of $\sim 140 \pm 6 \mathrm{pS}$ and a reversal potential of $+29.9 \pm 2.7 \mathrm{mV}$. (C) Electrical recordings from multiple channels in a planar lipid bilayer. Solutions were cis: $135 \mathrm{mM} \mathrm{NaF}, 15 \mathrm{mM} \mathrm{NaCl}, 0.5 \mathrm{mM} \mathrm{CalCl}$, $5.0 \mathrm{mM}$ MES- Na/HCl $\left(\sim 4.7 \mathrm{mM} \mathrm{Cl}^{-}\right) \mathrm{pH}$ 5.5; and trans: $150 \mathrm{mM}$ $\mathrm{NaCl}, 5.0 \mathrm{mM}$ MES-Na/HCl pH 5.5. Holding potential: $0 \mathrm{mV}$; pulses in $10 \mathrm{mV}$ steps to 140 and $-140 \mathrm{mV}$ in two epochs, respectively. Recordings at $\pm 140, \pm 130$, and \pm 120 $\mathrm{mV}$ were colored dark brown, red, and blue, respectively. (D) Single-channel currents versus transmembrane voltage $\left(V_{m}\right)$. Error bars: SD from three to five histogram-based measurements of singlechannel currents under each Vm. Fitting of the data with a linear function (dotted line) yielded a singlechannel conductance of $125 \pm 6 \mathrm{pS}$ with $150 \mathrm{mM} \mathrm{F}^{-} / \mathrm{Cl}^{-}$. (E) Small macroscopic currents recorded from a bilayer with multiple channels. cis: $150 \mathrm{mM} \mathrm{NaF}, 0.50 \mathrm{mM} \mathrm{CaCl}_{2}$, and $5.0 \mathrm{mM}$ MES- $\mathrm{Na} / \mathrm{HCl}, \mathrm{pH}$ 5.5, and trans: $135 \mathrm{mM} \mathrm{KCl}$, $15 \mathrm{mM} \mathrm{NaCl}$, and $5.0 \mathrm{mM}$ MES- $\mathrm{Na} / \mathrm{HCl}$, pH 5.5. Holding potential at $0 \mathrm{mV}$, and pulses in +10 and $-10 \mathrm{mV}$ steps (top). Recordings at $\pm 110, \pm 100$, and $\pm 90 \mathrm{mV}$ were colored in green, blue, and red, respectively, to show the channel switching events. (F). Steady state currents from the recordings in (E) plotted against $V_{m}$. Currents become smaller at negative range, because of more frequent channel closing (error bars are SD, $n=4$ ). The reversal potential $\left(E_{r e v}=-8.0 \mathrm{mV}\right)$ was used to estimate the permeation ratio $\left(P_{F} / P_{\mathrm{Cl}}\right)$ of $\mathrm{F}^{-}: \mathrm{Cl}^{-}$using a simplified GHK equation, $E_{r e v}=-R T / F \ln \left(P_{F}\left[F^{-}\right]_{o} / P_{C l}\left[C l^{-}\right]_{i}\right)$. The cis side is equivalent to the luminal side (outside) where the $\mathrm{CHGB}$ resides. From eight measurements, $P_{F} / P_{C l}=$ $1.2 \pm 0.2$. 
have made the estimated $\mathrm{P}_{\mathrm{Na}} / \mathrm{P}_{\mathrm{Cl}}$ slightly higher than the true value. Empty vesicles and vesicles prepared with CHGA were used as negative controls. Hundreds of bilayer membranes were analyzed to ensure high reproducibility and sufficient statistical power.

Comparing the measured single-channel conductance in Fig 4B with a chord conductance of $1.5 \mathrm{nS}$ from the small macroscopic currents in Fig S5C suggested that there were 11 channels in the patch recorded in Fig $4 \mathrm{~A}$. The average open probability $\left(<P_{0}>\right)$ of the channel remained at $\sim 100 \%$ within a range of $60 \mathrm{mV}$ above or below the reversal potential, and dropped to $70 \%$ at $80 \mathrm{mV}$ away from the reversal potential (the red line in Fig S5C). These patches lasted for 10-90 min, suggesting stable CHGB channel function. Under the ionic settings in Fig $4 \mathrm{~A}$, we found that $\mathrm{NaF}$ and $0.5 \mathrm{mM} \mathrm{CaCl}_{2}$ in the cis side helped to stabilize the bilayer membranes after vesicle fusion and minimize leak currents. When lipid mixtures known to have phase separation were used for CHGB reconstitution, for example, 1-palmitoyl-2-oleoyl-sn-glycero-3-phosphocholine (POPC) : brain sphingomyelin : cholesterol $=3: 1: 1$ in weight ratio, we sometimes observed a nonspecific leak channel with a single-channel conductance of $\sim 225( \pm 5)$ pS. Because the average single-channel conductance of CHGB is significantly smaller than 225 pS, it was quite easy to remove contaminating events from these leak channels by single-channel analysis. As negative controls, vesicles prepared with BSA, CHGA (Fig S4I), a CHGB deletion mutant lacking the CHGBMIF (CHGBDMIF), and CHGB-MIF itself all failed to generate any channel activity. A strong selectivity of anions over cations and the average $P_{0}$ over $V m$ ruled out the possibility that the measured conductance was contributed by non selective lipid ion channels previously observed in bilayers made of lipid mixtures that tend to exhibit phase separation (Mosgaard \& Heimburg, 2013). We therefore conclude that the observed anion channels were made by CHGB in membrane.

When we recorded the $\mathrm{CHGB}$ channels under symmetrical anions of $\sim 159 \mathrm{mM} \mathrm{F}^{-}$or $\mathrm{Cl}^{-}$, the measured single-channel conductance of CHGB is 125 pS (Fig 4C and D), fairly close to the 140 pS measured under asymmetrical anion conditions (Fig 4B). The small difference in single-channel conductance probably came from the different ionic conditions (Fig $4 \mathrm{C}$ versus $4 \mathrm{~A}$ ). When analyzing the recordings in Fig $4 \mathrm{~A}$ and $\mathrm{C}$, we determined the dominance of the $\mathrm{CHGB}$ anion channels based on two criteria: (i) the membrane patches should show a positive current ( $\mathrm{Cl}^{-}$influx) at $0 \mathrm{mV}$ when $15 \mathrm{mM} \mathrm{NaCl}$ (or $\mathrm{KCl}$ ) was present on the trans side for inducing vesicle fusion; and (ii) after salt balancing, the bilayer recordings at high voltages should show events that briefly reached 0 pA when all channels were closed (as in Fig S5A). Besides, our recordings showed subconductance states (as highlighted in Fig S5B), which will need detailed characterization in the future.

Comparison of recordings in Fig $4 \mathrm{~A}$ and $\mathrm{B}$ and those in Fig $4 \mathrm{C}$ and $\mathrm{D}$ suggests that the anion conduction of the CHGB channel could probably be sensitive to the anion concentrations on both sides of the membranes. To further evaluate the $\mathrm{Cl}^{-}$selectivity and anion sensitivity of the CHGB channel, we recorded single-channel currents with asymmetrical $\left[\mathrm{Cl}^{-}\right]$and symmetrical $\left[\mathrm{K}^{+}\right]$at pH 5.5 (cis/ trans: 1.5 / $15 \mathrm{mM} \mathrm{Cl}^{-}$versus 151.5 / $150 \mathrm{mM} \mathrm{K}^{+}$; Fig S5D and E, where an MES buffer was used without adding more $\mathrm{Cl}^{-}$during $\mathrm{pH}$ adjustment). K-isethionate was added to maintain high osmolality and ionic strength. Under such conditions, the recorded channels had no measurable outward current in the positive voltage range, suggesting no detectable conduction of $\mathrm{K}^{+}$. Analysis of the average single-channel currents at different negative voltages yielded an estimated chord conductance of $\sim 58$ pS (black line in Fig S5D, for $15 \mathrm{mM} \mathrm{Cl}^{-}$) and, by extrapolation, a reversal potential of $\sim+65 \mathrm{mV}$, close to the calculated Nernst potential $\left(E_{C l}=+58.4 \mathrm{mV}\right)$ of $\mathrm{Cl}^{-}$, but far away from that $(0 \mathrm{mV})$ of $\mathrm{K}^{+}, \mathrm{MES}^{-}, \mathrm{H}^{+}$, or $\mathrm{OH}^{-}$. The estimated reversal potential, being more positive than $E_{\mathrm{Cl}}$, suggested that the CHGB channel had a very low permeation of $\mathrm{K}^{+}$and the $P_{K} / P_{C l}$ might be much lower than the $P_{\mathrm{Na}} / P_{\mathrm{Cl}}$ measured from data in Fig 4B. The $\mathrm{CHGB}$ channel is thus $\mathrm{Cl}^{-}$-selective with very low $\mathrm{K}^{+}$conduction and its anion conduction is sensitive to $\left[\mathrm{Cl}^{-}\right]$as expected for a $\mathrm{Cl}^{-}$ channel.

When we measured reversal potentials of the CHGB channels in bi-ionic conditions, the estimated permeation ratio between $\mathrm{F}^{-}$and $\mathrm{Cl}^{-}$(Fig 4E and F) is $~ 1.2$. Good permeation of $\mathrm{F}^{-}$suggested possible conduction of $\mathrm{OH}^{-}$, which, however, should be very low in comparison with $\mathrm{Cl}^{-}$flux because the CHGB channel is sensitive to the concentration of the permeating ions in the range of 1.5 to $150 \mathrm{mM}$. The $\mathrm{OH}^{-}$concentration of $1.0 \times 10^{-8.5}$ or $1.0 \times 10^{-7.0} \mathrm{M}$ at pH 5.5 or pH 7.0, which is six to seven orders of magnitude lower than $\left[\mathrm{Cl}^{-}\right]$, would make its permeation across the CHGB channel negligible even though change of $\mathrm{pH}$ might modulate the channel activity. For reliable electric recordings in bi-ionic settings, we also checked that in higher voltage ranges $( \pm 80$ to $\pm 130 \mathrm{mV}$ ) closure of all channels reached zero current level briefly (as in Fig S5A) such that the reversal potentials determined from the current-voltage curves (Fig 4F) were reliable for estimating the bi-ionic permeation ratio.

Because only a small number of channels were measured in lipid bilayers, we questioned if a trace amount of contaminating anion channels might have contributed to the recorded activities. We separated $20 \mu \mathrm{g}$ of purified CHGB that had been kept in a cold room for $\sim 4 \mathrm{~d}$, and detected two faint smaller bands (1 and 2 in Fig $\mathrm{S1B})$. When the full-length $\mathrm{CHGB}$ band and the two shorter bands were cut out and digested for HPLC/MS analysis and proteomic identification (Tables S1 and S2), all three bands were heavily dominated by CHGB peptides. The two smaller bands shared five peptides and were therefore CHGB degradation products. Other candidates had much fewer matched peptides, less than six for the CHGB band and only one for two smaller bands. Among them, only KVQT member 5 (accession number E9Q9F in Table S1) is a $\mathrm{K}^{+}$ channel, but without an anion channel. When we compared the scanned density of the bands (right panel in Fig S1B), the two degradation bands, usually absent in fresh samples (Fig S1A), were $\sim 1.5 \%$ of total CHGB. Results from diluted proteins in the same gel suggested that any other contaminant that is more than $0.12 \%$ of the total mass would have been detected. The purified CHGB thus had $>99.8 \%$ purity, making it very unlikely $(<0.12 \%)$ for a contaminating anion channel to account for the observed channel activities in lipid bilayers.

\section{CHGB conducts $\mathrm{F}^{-}$and $\mathrm{Cl}^{-}$better than other anions}

Because it was critically important to stringently rule out the possibility of trace contaminant channels yielding the measured channel activity in Fig 4, we quantified anion flux from a large number $\left(>1.0 \times 10^{11}\right)$ of $\mathrm{CHGB}$ vesicles. The $\mathrm{Ag} / \mathrm{AgCl}$ measurement in 
Fig $3 \mathrm{C}$ was limited to $\mathrm{Cl}^{-}$, not other anions; nor was it highly stable because of slow mixing of valinomycin and drifts of electrode potential. We instead implemented a light scattering-based flux assay (Fig S3F) (Stockbridge et al, 2013) by both steady-state and stopped-flow fluorimetry. In both systems, valinomycin triggers $\mathrm{K}^{+}$ efflux and anion release via CHGB from vesicles, resulting in a sudden drop of intravesicular osmolality and collapse of vesicles into ellipsoids that scatter more light (Fig S3F). Extrusion was performed to control vesicle dimensions so that large-sized vesicles would not dominate the measured signals. As a positive control, the bacterial $\mathrm{Cl}^{-} / \mathrm{H}^{+}$cotransporter (EriC; 2:1 exchanger) in vesicles yielded a robust increase in light scattering (Fig $\mathrm{S} 4 \mathrm{H}$ ) (Stockbridge et al, 2013) when compared with empty vesicles. The CHGB vesicles prepared in parallel delivered a strong signal (Figs S4H and 5A) at both $\mathrm{pH} 7.4$ and 5.5. The increase in steady-state light scattering saturated within the 10 -s break for adding valinomycin, slightly quicker than the 20-s duration of $\mathrm{Cl}^{-}$efflux in Fig 3C. A nonspecific $\mathrm{Cl}^{-}$-channel blocker, DIDS (5,4'-diisothiocyanatostilbene-2,2'-disulfonic acid), was able to block the strong flux signal with an apparent $k_{D}=0.9 \mu \mathrm{M}$ (Fig 5B), reflecting an affinity which is one to two orders of magnitude higher than the DIDS affinity for all ClC-family proteins.

As negative controls, recombinant $\mathrm{CHGA}$ in vesicles produced no signal (Fig S4I and J); nor did CHGB-MIF or CHGBAMIF (Fig 5C and D).
Hence, CHGB-MIF alone is insufficient to form the anion channel although it is indispensible to a functional channel. Considering the negatively charged residues contributing to anion selectivity of other $\mathrm{Cl}^{-}$channels (Maduke et al, 2000), we deleted a short loop (residues: 540-551; CHGB- $\triangle$ L1) right after helix 2 (Fig S4C) and mutated three negatively charged residues in the loop to Ala (marked with arrows in Fig S4C and D). The same amount of different mutant proteins was reconstituted into the same amount of $(5 \mathrm{mg} / \mathrm{ml})$ lipids to allow comparison among them by the flux assay (Fig 5E). CHGB- $\Delta$ L1 had significantly lower flux than wild-type CHGB. Mutation of the wellconserved E558 blocked approximately $40 \%$ of the flux signal, whereas neither E545A nor E552A incurred significant effect (Fig 5E). These data further demonstrate that helix 3 and the loop ahead of it are important for ion conduction of the CHGB channel (Fig S4D).

We next compared the relative ion selectivity of the CHGB channel by loading different anions into vesicles for flux assays. Our data show that the $\mathrm{CHGB}$ channel conducts $\mathrm{Cl}^{-}$and $\mathrm{F}^{-}$much better than $\mathrm{Br}^{-}, \mathrm{I}^{-}, \mathrm{NO}_{3}^{-}, \mathrm{SCN}^{-}$, formate, or citrate (Fig 5F), suggesting that under the conditions, especially the high positive potential inside the vesicles, for the light scattering-based flux assays, the CHGB channel is more selective than the other well-known $\mathrm{Cl}^{-}$channels or transporters (Maduke et al, 2000; Fahlke, 2001). The equally robust light scattering-based flux signals for $\mathrm{F}^{-}$and $\mathrm{Cl}^{-}$are consistent with the measured permeation ratio $P_{F} / P_{C l}=1.2$ (Fig 4F).
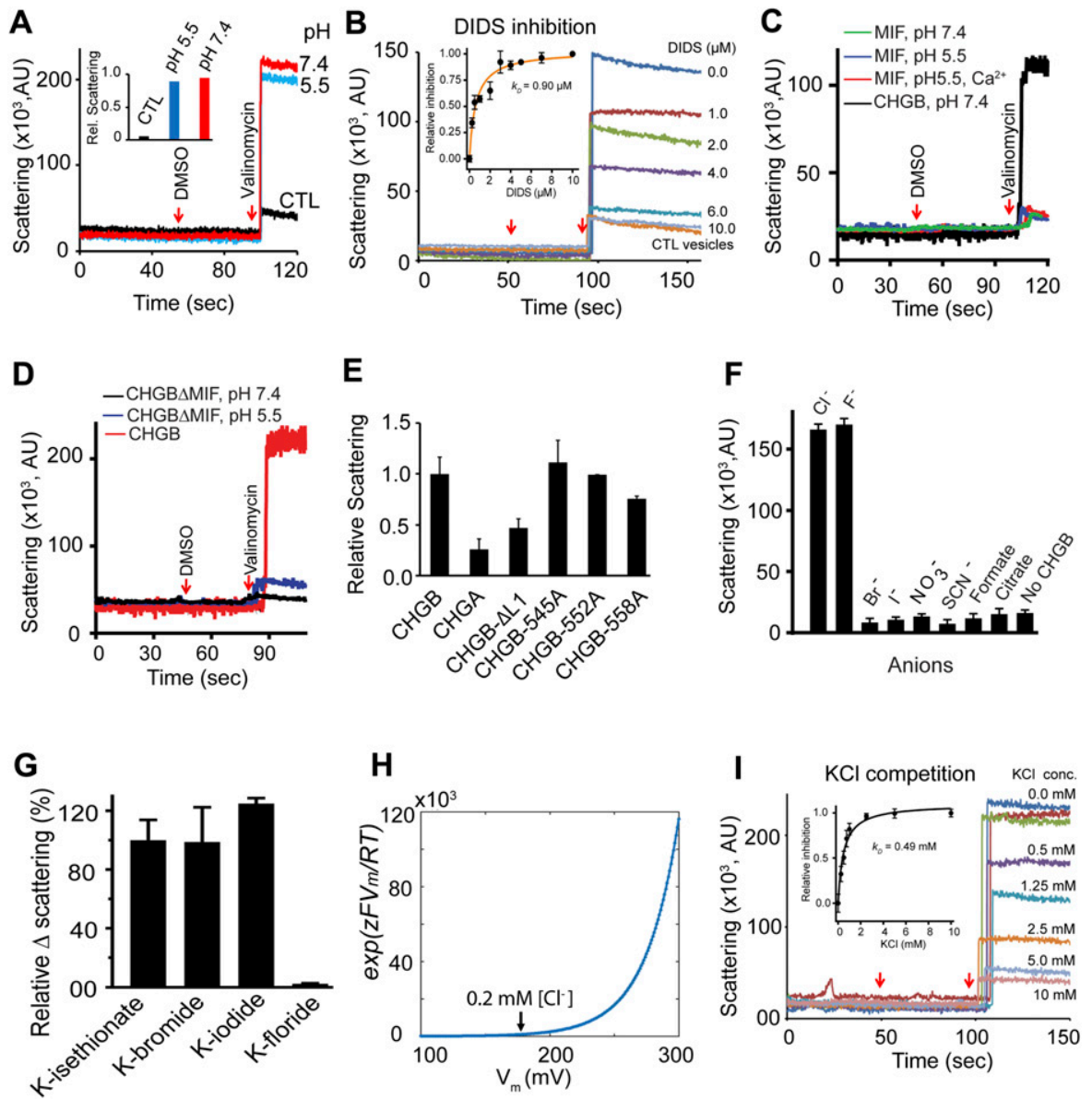

Figure 5. CHGB conducts $\mathrm{F}-$ and $\mathrm{Cl}-$ better than other anions.

(A). Light scattering-signals measured from vesicles with (red and blue for $\mathrm{pH} 7.4$ and 5.5, respectively) and without (black) CHGB. A 30-s pause for adding DMSO or valinomycin was not included. (B) The CHGB proteoliposomes were treated with different concentrations of the DIDS for 5 min at RT before experiment. DIDS inhibits CHGB-mediated $\mathrm{Cl}^{-}$flux. Red arrows indicate the addition of DMSO and valinomycin. Inset: change in the scattering was plotted against the DIDS concentration. Fitting with a Hill equation yielded a $k_{D}=0.9 \mu \mathrm{M} ; \mathrm{n}=1.0$. (C) Flux assay from vesicles with and without CHGB-MIF under different conditions in comparison with CHGB vesicles (black). (D) Flux assays of liposomes with and without CHGB $\triangle$ MIF at two different $\mathrm{pH}$ 's. Wild-type control in red. (E) Flux assays of liposomes containing CHGA, CHGB, and CHGB mutant proteins. Residues E545, E552, or E558 in the loop (L1) between helix 2 and helix 3 were mutated to alanine. (F) Relative anion selectivity of CHGB channel based on the flux assay. Error bars represent SD from three different sets of experiments. (G). Instead of $300 \mathrm{mM} \mathrm{K-}$ isethionate, $300 \mathrm{mM} \mathrm{KF}, \mathrm{KBr}$ or $\mathrm{KI}$ was introduced to the extravesicular side against $300 \mathrm{mM} \mathrm{KCl}$-loaded vesicles. $\mathrm{Br}^{-}$or $\mathrm{I}^{-}$supported significant flux signal. But, $300 \mathrm{mM} \mathrm{F}^{-}$abolished the flux. Error bars: SD, $\mathrm{n}=3$. $(\mathbf{H})$. Calculated correction factor for valinomycin-mediated $\mathrm{K}^{+}$transport because of steady state Nernst potential for $300 \mathrm{mM} \mathrm{KCl}$-loaded CHGB vesicles with $0-5 \mathrm{mM} \mathrm{KCl}$ outside. (I) Flux assay from $300 \mathrm{mM} \mathrm{KCl-loaded} \mathrm{CHGB}$ vesicles in the presence of $0-10 \mathrm{mM} \mathrm{KCl}$ and $300 \mathrm{mM} \mathrm{K}$ isethionate in the extravesicular side. Vesicles had 1:10,000 PLR of CHGB: egg PC. Three independent sets of vesicles prepared from separate cell cultures $(n=3)$ were used to ensure high statistical power. Inset: change in the scattering was plotted against the $\mathrm{KCl}$ concentration and fitting with a Hill equation yielded a $k_{D}=0.49 \mathrm{mM}$ and $\mathrm{n}=1.0$. 
The ion selectivity data (Fig 5F) make two predictions. One is that extravesicular $300 \mathrm{mM} \mathrm{Br}^{-}$or I ${ }^{-}$should not affect the light scatteringsignals, whereas $\mathrm{F}^{-}$should completely stop it, precisely what our experiments showed (Fig 5G). The other is that a low concentration of extravesicular $\mathrm{Cl}^{-}$should shift the initial steady-state Nernst potential of $\mathrm{Cl}^{-}\left(E_{C l}\right)$ across vesicle membranes and significantly inhibit $\mathrm{Cl}^{-}$flux because of a voltage-dependent factor affecting the rate of valinomycin-

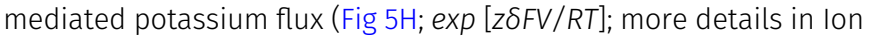
flow through the $\mathrm{CHGB}$ requires a fast-conducting channel, not a slow-acting transporter section). Indeed, extravesicular $\left[\mathrm{Cl}^{-}\right]$of 0.1 to $2 \mathrm{mM}$ significantly impaired the light scattering-signal with an apparent $k_{D}=0.49 \mathrm{mM}$ (Fig 5I).

\section{High cooperativity among CHGB subunits in forming functional channels}

Steady-state fluorimetry measurement cannot detect fast channelopening events because of slow and uneven equilibration of valinomycin among vesicles. A stopped-flow fluorometer (Hayner et al, 2014) with a dead time of 2 ms was used to overcome this limit through fast mixing. We compared the light scattering-signals by both steady-state and stopped-flow fluorimetry, and titrated PLRS of CHGB vesicles with a fixed lipid concentration of $\sim 0.4 \mathrm{mg} / \mathrm{ml}$. When $\mathrm{PLR}<1: 50,000$, no signal was detected in either system (Fig $6 \mathrm{~A}$ and $\mathrm{B})$. When PLR reached 1:1,000, the signal approached its maximum. All stopped-flow traces showed instantaneous jumps, suggesting a fast efflux of $\mathrm{K}^{+} / \mathrm{Cl}^{-}$within $2 \mathrm{~ms}$. Because of fast and even partitioning of valinomycin into individual vesicles, the instantaneous jumps in light scattering reflected a sudden change in vesicle shape after $\mathrm{K}^{+} / \mathrm{Cl}^{-}$efflux. When the measurements during the first $5 \mathrm{~s}$ from the steady-state fluorimetry and the first $40 \mathrm{~ms}$ of the stopped-flow data (Fig 6C and D) were plotted against [CHGB] and fitted with a Hill equation (Fig 6E), the estimated Hill COefficients were $\sim 1.2$ from the steady-state measurement and $\sim 4.2$ from the stopped-flow data, suggesting high positive cooperativity among CHGB subunits in forming a functional channel. The steadystate data revealed less cooperativity probably because of uneven and slow mixing of valinomycin with vesicles and the complications resulted from water movement in response to osmolality change. When the data in Fig 6E were plotted against the average number of CHGB subunits per $100 \mathrm{~nm}$ vesicle (Fig 6F), the threshold for strong signals occurred at $~ 4 \mathrm{CHGB}$ subunits per vesicle, and nearly $80 \%$ of the maximum signal was achieved with $\sim 8 \mathrm{CHGB}$ subunits per vesicle.

Random reconstitution and a Poisson distribution suggest that the CHGB channel is a tetramer. CHGB dimers were randomly distributed among individual vesicles. According to the parameters for our vesicles (Table S3), a PLR $=1: 10,000$ yielded an average number $(\lambda)$ of CHGB monomers per 100-nm vesicle of $\sim 8$. The Poisson distribution allows us to evaluate the fraction of vesicles that might not have enough CHGB subunits to form a functional channel. Given that $P(k)$ represents the probability of vesicles containing $k$ copies of $\mathrm{CHGB}$ monomers, where $k$ is a discrete number $(0,1,2,3, \ldots)$ and $\lambda$ the average number of CHGB monomers per vesicle that was set by adjusting the PLR of the CHGB vesicles, we calculated the fractions of vesicles, $P(k<N)$, that would each have less than $N$ copies of CHGB monomers with $N=2,3, \ldots, 8$. If a functional channel needs $N$ subunits, then $P(k<N)$ represents the theoretically predicted fraction of vesicles having no functional channel. The predictions were listed together with experimental data (last column) of Table 1. Least squares analysis of the experimental data and $P(k<N)$ (total variances in Table 1) found $N=4$ (bold in Table 1), meaning that each channel should have four subunits (more details in A Poisson distribution of $\mathrm{CHGB}$ subunits among vesicles predicts tetrameric stoichiometry of functional channels section). Given the stable CHGB dimers in detergents, a channel is more likely to have an even number of subunits. A tetramer is thus probably a dimer of two dimers.

The strong signals in the light scattering-based flux assays predict that valinomycin may form a $\mathrm{K}^{+}$-conducting channel to match the fast anion flow. The quick, sudden change in vesicle shape requires fast $\mathrm{K}^{+}$flux within the $2 \mathrm{~ms}$ mixing time. Varying [valinomycin] per vesicle was hence expected to affect the signal. Titration of [valinomycin] in the stopped-flow measurement (Fig 6G) found that when [valinomycin] $<0.25 \mu \mathrm{M}$, the flux signal was almost non detectable, whereas 2-5 $\mu \mathrm{M}$ delivered the maximal signal. Fitting of the dose response data with a Hill equation (Fig $6 \mathrm{H}$ ) identified a Hill coefficient of $n=2.6$, indicating high positive cooperativity among valinomycin molecules in moving $\mathrm{K}^{+}$across membrane. These data accord well with our observation that $0.1 \mu \mathrm{M}$ valinomycin triggered no detectable flux signal. The cooperativity suggests that valinomycin function as trimers or high-order oligomers in membrane, reminiscent of the dimeric valinomycin channel in ultrathin membranes (Gliozzi et al, 1996). To match the $\mathrm{Cl}^{-}$flux, each valinomycin oligomer must have a conductance $>3 \mathrm{pS}$, a lower limit for an uncharacterized valinomycin channel.

\section{Discussions}

\section{CHGB-membrane interaction and formation of anion channel}

Our data collectively support a working model that CHGB inserts itself into lipid membranes, which promotes CHGB oligomerization by shifting a dynamic equilibrium between the dimers and the predicted tetramers, and generates a functional $\mathrm{Cl}^{-}$channel by spanning two leaflets of a biomembrane (Fig 7). Even though we cannot exclude the possibility that the CHGB organizes the lipids to form a lipid ion channel, the nonselective nature of previously reported lipid ion channels and the anion selectivity of the $\mathrm{CHGB}$ channel (Figs 3A-C, 4A, B, S5C, and 5F) together suggest that the CHGB channel is probably formed by the protein in the presence of the lipids. This explanation also agrees with the observations that the CHGB needs no specific lipids to form the anion channel because the flux assays found that the channel functions well in 1,2-dioleoyl-sn-glycero-3-phosphocholine (DOPC), 1-palmitoyl-2-oleoylsn-glycero-3-phosphocholine (POPC), egg phosphocholine (PC), 1-palmitoyl-2-oleoyl-sn-glycero-3-phosphoethanolamine (POPE)/1palmitoyl-2-oleyol-sn-glycero-3-phosphoglycerol (POPG) (POPE/ POPG = 3:1 weight ratio) mixture, or DOPC/sphingomyelin/cholesterol mixture. Because eukaryotic cells have sufficient ER membranes, nascent CHGB molecules should be preferentially membrane-associated from the luminal side. Both helices 1 and 3 are involved in the membrane insertion (Fig $3 \mathrm{I}$ and $\mathrm{J}$ ) and the loop before helix 3 is important for anion conduction (Fig 5E). Moreover, the CHGB-membrane interaction may 
A Steady-state Flourimetry
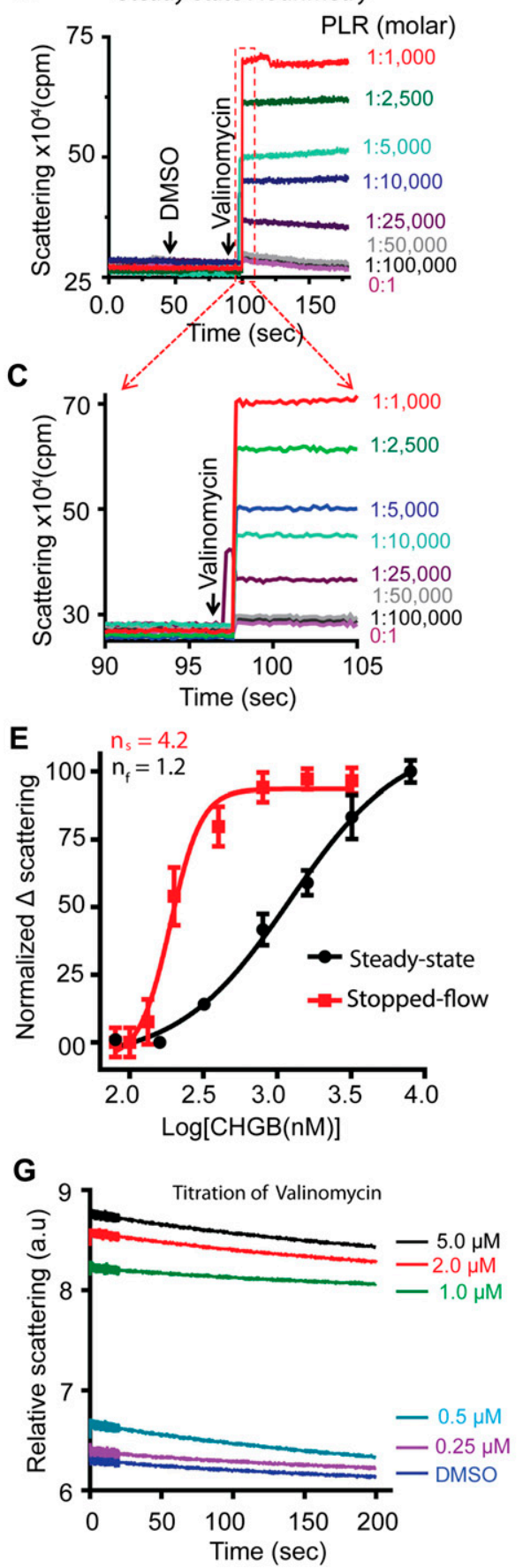

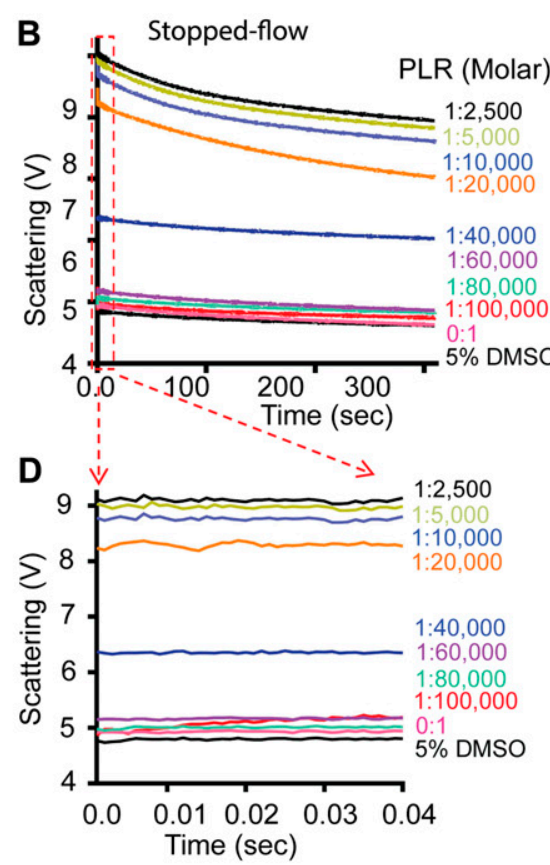

$\mathbf{F}$

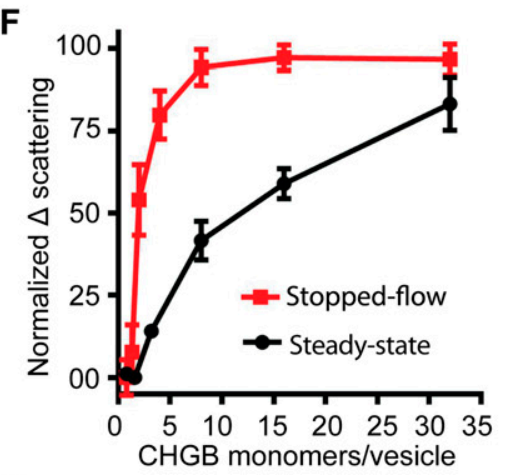

H

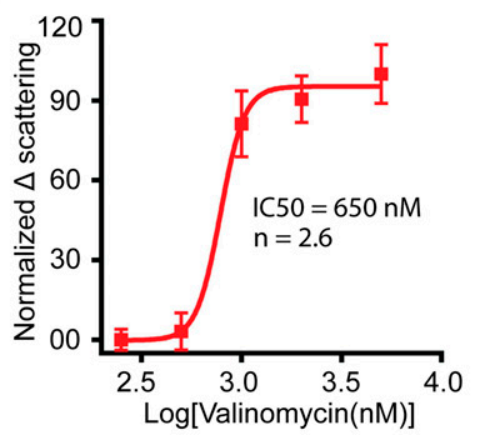

Figure 6. Fast kinetics of $\mathrm{Cl}^{-}$release from the CHGB channels in vesicles.

(A) $300 \mathrm{mM} \mathrm{KCl-loaded} \mathrm{vesicles} \mathrm{changed} \mathrm{into} 300 \mathrm{mM}$ $\mathrm{K}$-isethionate right before the assay. Time-lapsed light scattering was measured at $600 \mathrm{~nm}$ in a Fluoromax-4. Vesicles of different PLRs were prepared in the same batch. Adding DMSO triggered no signal, but adding $1.0 \mu \mathrm{M}$ valinomycin did. (B) Time-lapsed light scattering $(610 \mathrm{~nm})$ measured in a stopped-flow system, by mixing equal volumes of vesicles and $2.0 \mu \mathrm{M}$ valinomycin in buffer. 5\% DMSO solution was added as negative control. Vesicles of PLR $=1: 1,000$ used to set a proper accelerating voltage for the PMT tube to have the broadest dynamic range. (C) Expanded region in the red box in panel $A$. (D) Expanded region in the red box in panel B. Data from the first $40 \mathrm{~ms}$ after the dead time of $\sim 2$ ms for mixing are shown. (E) Average signals from the first 5-s data in (C) (black) and those from the first $40 \mathrm{~ms}$ in (D) (red) are plotted against [CHGB]. Fitting with Hill equations (solid lines) generated different Hill coefficients. Steady state data from four different datasets ( $n=4$; error bars are SD); Stopped-flow data from two sets of triplicate measurements $(n=6$; error bars are SEM). (F) The data in panel $E$ were plotted against the average number of CHGB monomers per $100-\mathrm{nm}$ vesicle. The threshold for generating a significant signal is $\sim 4$ monomers per vesicle for both measurements. (G) Titrating valinomycin for the lightscattering from $\mathrm{CHGB}$ vesicles in the stopped-flow system. The $\mathrm{CHGB}$ vesicles had $\mathrm{PLR}=1: 25,000$. More vesicles than those in panel $B$ were used to boost the signal, which also increased the baseline signal (buffer + DMSO). Three triplicate measurements were obtained ( $n=9$; error bars are SEM). $(\mathbf{H})$ The normalized signal from panel $\mathrm{G}$ were plotted again [valinomycin] and fitted with a Hill equation to yield a Hill coefficient of $\sim 2.6$. promote high-order oligomeric forms in a calcium-dependent way (Fig S2B-F) and can remodel the bilayer membranes into nanostructures (Fig 2F). For simplicity, we depict a channel pore with its two opposing monomers, omitting other subunits in Fig 7. Once a channel is formed, it opens most of time (Figs 4 and S5C), making its resident membrane highly permeable to $\mathrm{Cl}^{-}$, but not other anions except $\mathrm{F}^{-}$. Inside the secretory granules, such high selectivity would be useful in keeping metabolic anions from becoming concentrated into the secretory granules and being dumped as waste.

\section{Membrane-insertion induces CHGB channel formation}

Our data show that with sufficient lipids both CHGB and CHGA are fully reconstituted in the liposomes (Figs $1 \mathrm{E}$ and S4I), but CHGA does not form a channel. We hence propose that the full-length CHGB may be preferentially in membrane in the regulated secretory pathway. Because both ER and Golgi membranes have their own $\mathrm{Cl}^{-}$channels, the CHGB channel is probably nonessential for ER and Golgi. The Cysloop domain of the CHGB guides its delivery to the secretory granule 
Table 1. A Poisson distribution of CHGB subunits among vesicles and the most probable stoichiometry of a functional channel.

\begin{tabular}{|c|c|c|c|c|c|c|c|c|}
\hline & \multicolumn{7}{|c|}{ Fraction of vesicles have fewer than $\mathrm{N}$ monomers, $P(k<N)$} & \multirow{2}{*}{ Stopped-flow data } \\
\hline & 2 & 3 & 4 & 5 & 6 & 7 & 8 & \\
\hline \multicolumn{9}{|c|}{$\lambda,<\mathrm{CHGB}>$ /vesicle } \\
\hline 0.8 & 0.81 & 0.95 & 0.99 & 1 & 1 & 1 & 1 & 1 \\
\hline 1.67 & 0.503 & 0.765 & 0.911 & 0.972 & 0.993 & 0.998 & 1 & 0.912 \\
\hline 2 & 0.406 & 0.677 & 0.857 & 0.947 & 0.958 & 0.983 & 0.996 & 0.846 \\
\hline 4 & 0.092 & 0.238 & 0.434 & 0.629 & 0.785 & 0.889 & 0.949 & 0.481 \\
\hline 8 & 0.003 & 0.014 & 0.042 & 0.1 & 0.191 & 0.313 & 0.453 & 0.19 \\
\hline Total variances & 0.583 & 0.143 & 0.024 & 0.044 & 0.112 & 0.208 & 0.318 & \\
\hline
\end{tabular}

Bold value represents the optimal fitting for the experimental data.

where it executes its specific intracellular functions as investigated in a separate paper (Yadav et al, unpublished), which studies the function of "tightly membrane-associated" CHGB on the cell surface (Pimplikar \& Huttner, 1992) and connects the CHGB channel function with granule maturation ex vivo and in vivo.

Membrane insertion of an amphipathic protein without canonical transmembrane segments to form ion channels has multiple precedents: Hemolysin, C-type lectin, VopQ, etc., are a few (Ramarao \& Sanchis, 2013; Sreelatha et al, 2013; Mukherjee et al, 2014). Thermodynamically, oligomerization of individual subunits and interactions among them and with lipids increase entropy of water molecules liberated from hydrophobic surfaces, such as those from helices 1 and 3 in CHGB (Fig $3 \mathrm{I}$ and J), and overcome the energy cost of dehydration and membrane insertion.

The observations of both heat-stable, soluble fractions and "tightly membrane-associated form" of CHGB may reflect two different biochemical conditions of CHGB (Benedum et al., 1986, 1987; Pimplikar \& Huttner, 1992; Yoo, 1995b). CHGB-coated 25 nm nanoparticles may reconcile these observations. These nanoparticles are densely packed with proteins and are expectably heat-stable and soluble by burying CHGB's hydrophobic domains. It would be interesting to examine whether CHGB in the soluble (or heat-stable) fractions takes similar structures as the $25 \mathrm{~nm}$ nanoparticles (Fig 2B-D). Similarly, structures of CHGB dimers, tetramers, and higher order oligomers will be needed to reveal their allosteric changes during channel formation. Further, the sidedness of CHGB insertion in membrane endows special functions such as membrane remodeling and $\mathrm{pH}$ - or $\mathrm{Ca}^{2+}$-dependent regulation, which await more investigations.

A "tightly membrane-associated form" of the CHGB is resistant to treatment of basic $\mathrm{pH}$, but soluble by Triton X-114 (Pimplikar \& Huttner, 1992). Beside a good way to retain the full-length protein and separate it from the CHGB peptides, such a mechanism is consistent with our working model because calcium-induced CHGB aggregates (Fig S2B-F) or CHGB-packed nanoparticles might send some full-length $\mathrm{CHGB}$ proteins into the lumen through membrane remodeling. It remains unknown what physiological roles the 25-nm particles, if they form inside cells, would play and how the CHGB in the luminal side is distributed and regulated.

Nevertheless, the CHGB channel activity is an intrinsic property because of the channel activity in different membrane systems tested so far. Considering the highly conserved helices (Fig S4B and D) and the key residues (e.g., E558 in Figs 5E and S4D), we propose that $\mathrm{Cl}^{-}$conductance represents a universal property within the CHGB subfamily of granin proteins. CHGB channels are quite different in sequence, structure, and functional properties from the six families of chloride channels-CTFR, the large family of glycine/ GABA receptor channels, the ClC-family of channels/transporters, the volume-regulated anion channels, the uncharacterized large conductance $\mathrm{Cl}^{-}$channels, and the $\mathrm{Ca}^{2+}$-regulated $\mathrm{Cl}^{-}$channels of TMEM16A, TMEM16B, and bestrophins (Qu et al, 2006; Duran et al, 2010; Hwang \& Kirk, 2013; Pedersen et al, 2016). CHGB channels do not contain the canonical transmembrane $\alpha$-helices; nor the betabarrel structure of VDAC (voltage-dependent anion conductance) in mitochondria. They have better anion selectivity, higher DIDSbinding affinity, and larger conductance. These make the CHGB channels a new family of $\mathrm{Cl}^{-}$channels, but a very distant one from the others.

\section{$\mathrm{U}_{2} \leftrightharpoons \mathrm{U}_{\mathrm{n}}(\mathrm{n} \geq 4)$ in detergent solution $\mathrm{U}_{2} \leftrightharpoons \mathrm{U}_{\mathrm{n}}(\mathrm{n} \geq 4)$ in membrane}

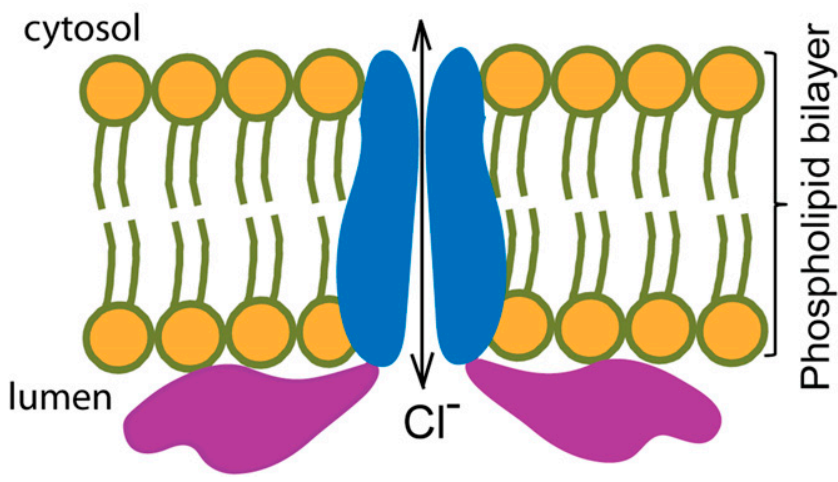

Figure 7. A working model for CHGB membrane insertion and channel formation.

Dynamic equilibrium exists between CHGB dimers and oligomers (probably tetramers, $U_{n}$ ). In detergents, dimers are favored while in membrane oligomers (tetramers) are. Bottom: a scheme for CHGB insertion into membranes from the luminal side, forming a $\mathrm{Cl}^{-}$channel and part of each $\mathrm{CHGB}$ subunit resides on the luminal surface. 


\section{Two forms of CHGB in native tissues and their relation to CHGB ion channel}

CHGB has been prepared in both soluble and membrane-bound fractions in the past (Benedum et al, 1987). The amphipathic nature of CHGB makes it feasible to distribute between these two states, similar to the observed transition of melittin from soluble tetramers to membrane-integrated oligomers that lead to hemolysis or the oligomerization of soluble monomeric human C-type Lectin RegIII $\beta$ and Regllly in membranes that leads to membrane breakdown in $G^{-}$ and $\mathrm{G}^{+}$bacteria (Laine et al, 1988; Miki et al, 2012; Mukherjee et al, 2014). The soluble form of CHGB in the secretory granules is likely dominated by CHGB dimers and/or their complexes with themselves, other proteins, or lipids. It may contain partially processed CHGB by proteolysis. The membrane-bound form is very likely dominated by tetramers or high-order oligomers. These two forms together may reconcile the conflicting reports in literature and reveal new physiological properties of CHGB in two different states.

\section{Conclusions}

CHGB is capable of inserting itself into membranes and forming a $\mathrm{Cl}^{-}$channel with anion selectivity higher than other known families of $\mathrm{Cl}^{-}$channels. The unique amphipathic features of the CHGB subfamily proteins make them a new family of $\mathrm{Cl}^{-}$channels that function in the regulated secretory pathway.

\section{Materials and Methods}

\section{Purification of recombinant CHGB and its mutants expressed in sf9 cells}

We used baculovirus to over-express CHGB proteins (Invitrogen). Preparation of other constructs followed the same general procedure unless separately stated. The cDNA of mouse CHGB gene (mChgb) was cloned from a pcDNA3.1 plasmid (a gift from Dr. Barbara Ehrlich at Yale University) into the pFastBac 1 vector (Invitrogen). Cloning was monitored by mapping with restriction endonucleases and PCR-based sequencing. Escherichia coli clones with the recombinant bacmids were isolated after transformation of E. coli DH10Bac cells with mChgb/pFastBac1 plasmid and blue/ white-screening of the transformed colonies. The bacmid DNA was used to transfect monolayers of sf9 cells using CellFECTIN II reagent (Invitrogen). Recombinant viruses were harvested 72-96 h after transfection (P1), and further amplified twice to obtain higher titer viruses (P2 and P3). Sf9 cells in SFM-900 II with $2 \% \mathrm{vol} / \mathrm{vol}$ heat-inactivated FBS and $1 \times$ penicillin/streptomycin were infected with recombinant viruses with $\mathrm{MOI}$ of one. Cells were harvested $48 \mathrm{~h}$ after infection, and lysed in a buffer made of $50 \mathrm{mM}$ Tris, $\mathrm{pH}$ 8.0, 10\% glycerol, 5.0 mM DTT, 1.0 mM EDTA, 1.0 mM PMSF, 2.0\% NP40, 1× protease-inhibitor mix (Sigma-Aldrich), and $1.0 \mu \mathrm{g} / \mathrm{ml}$ each of leupeptin, pepstatin, and aprotinin. After $1 \mathrm{~h}$ extraction in the cold room, cell lysates were centrifuged at $100,000 \mathrm{~g}$ for $1 \mathrm{~h}$ at $4^{\circ} \mathrm{C}$.
The clear supernatant was collected and applied directly to a preequilibrated Q-sepharose FF column (Amersham Biosciences). The column was washed with buffer A (20 mM Tris, pH 8.0, $100 \mathrm{mM}$ $\mathrm{NaCl}, 2.0 \mathrm{mM} \beta-\mathrm{ME}, 0.050 \%$ Triton $\mathrm{X}-100$, and $0.5 \mathrm{mM}$ PMSF), and eluted with a three-step gradient of buffer $\mathrm{B}$ containing $2.0 \mathrm{M} \mathrm{NaCl}$. CHGB-containing fractions were pooled. $25 \%$ ammonium sulfate (final) was added to precipitate CHGB protein. The pellet was collected by centrifugation and dissolved in buffer $C$ containing $20 \mathrm{mM}$ Tris, pH 8.0, $100 \mathrm{mM} \mathrm{NaCl}, 2.0 \mathrm{mM} \beta$-ME, 0.050\% Triton X-100 of reduced absorbance, and 0.25 mM PMSF. The dissolved mixture was applied to a Ni-IDA column (Amersham Biosciences), washed, and eluted with $300 \mathrm{mM}$ imidazole in the buffer. The eluted protein was concentrated and further purified by size-exclusion FPLC (fast protein liquid chromatography) using a Superose 6 10/30 GL column (Pharmacia Biotech). The CHGB fractions were collected and concentrated to $\sim 5.0 \mathrm{mg} / \mathrm{ml}$ using a 30,000 MWCO filter (Millipore).

The $\mathrm{CHGB}$ protein concentration was estimated by $\mathrm{OD}_{280}$ using a calculated extinction coefficient of $82,405 \mathrm{M}^{-1} \mathrm{~cm}^{-1}$. Purified CHGB was subjected to $10 \%$ SDS-PAGE to confirm its purity. For Western blot, the protein bands in an SDS-PAGE gel were transferred to a PVDF membrane, immunostained with monoclonal antibodies, and visualized by chemiluminescence (SuperSignal West Pico; Thermo Fisher Scientific).

\section{Expression and purification of individual GHGB fragments from bacteria}

Different fragments of mouse $\mathrm{CHGB}$, including $\mathrm{CHGB}-\mathrm{F} 1, \mathrm{CHGB}-\mathrm{F} 2$, CHGB-F3, CHGB-F4, CHGB-Hex, CHGB-Helix2, CHGB-Helix3, CHGBCys, and CHGB-Cterm (Fig 3D), were individually subcloned into the pGEX-kg (Novagen) vector containing an N-terminal GST-tag. The fusion proteins were over-expressed in E. coli BL21 (DE3) host cells (Novagen). After cell lysis and centrifugation, the protein was affinity-purified with Glutathione Sepharose 4B (GE Healthcare). The eluted protein was further purified by size-exclusion FPLC in a Superdex 200 column (GE Healthcare) in a buffer containing $20 \mathrm{mM}$ Tris- $\mathrm{HCl}, \mathrm{pH}$ 8.0, $200 \mathrm{mM} \mathrm{NaCl}, 1.0 \mathrm{mM}$ EDTA, and $1.0 \mathrm{mM}$ DTT with $0.050 \%$ Triton $\mathrm{X}-100$.

\section{Preparation of proteoliposomes}

Reconstitution follows closely a published protocol (Lee et al, 2013). 5 or $10 \mathrm{mg}$ of egg PC lipids (Avanti Polar Lipids) was dried in a glass testtube with argon gas, vacuum-treated for $1.0 \mathrm{~h}$, hydrated with autoclaved MilliQ water, and vortexed before being sonicated in an iced water-bath sonicator to make small unilamellar vesicles. $\mathrm{N}$-decyl $\beta$-D maltopyranoside (DM; Affymetrix-Anatrace) was added to $40 \mathrm{mM}$. After 5-6 h at RT, the detergent/lipid solution became almost completely transparent. Lipid/detergents and proteins in detergents were mixed in a desired PLR and rocked overnight in a cold room. Next day, Bio-Beads were added stepwise to gradually remove detergents. After reconstitution, the vesicle solution became cloudy, and was aliquoted, flash-frozen in liquid nitrogen, and stored at $-80^{\circ} \mathrm{C}$ until experimental use. Control vesicles were prepared similarly without protein. Other 
proteins were treated in the same procedure, even though some of them were soluble and did not get into the vesicles at all.

For vesicle floatation assay, reconstituted vesicles were mixed with $20 \%$ Ficoll 400 by 1:3 volume ratio. The mixture $(\sim 0.3 \mathrm{ml})$ was the bottom layer, above which $10 \%$ and $5 \%$ Ficoll were loaded sequentially. The gradient was centrifuged at $250,000 \mathrm{~g}$ for $3.0 \mathrm{~h}$ at $4^{\circ} \mathrm{C}$. The vesicles migrated to the top $5 \%$ layer and were clearly visible as a narrow band in the gradient. Non reconstituted proteins stayed at the bottom. The gradients were fractionated for protein detection.

\section{Recordings of single-channel events in bilayer lipid membranes}

The CHGB in egg PC vesicles at $0.50 \mathrm{mg} / \mathrm{ml}$ in varying PLR of 1:10,000 to 1:2,000 was first tested in 150 to $300-\mu \mathrm{m}$ bilayer membranes. We observed that immediately after vesicle fusion the membranes were quiet and stable, but in some cases there were sudden changes in a short while (within a few minutes) with multiple highconductance events, which usually became quiet again after a few tens of seconds. These observations have defied our efforts to record macroscopic currents from dozens or hundreds of CHGB channels.

Instead, vesicles with PLR of 25,000 to $1: 10,000$ led to small currents (usually $<100 \mathrm{pA}$ at $100 \mathrm{mV}$ ) from a handful of channels. The channels remained mostly open in low Vm $([-50,+50 \mathrm{mv}])$, but frequently closed in higher voltages ( $\mathrm{mm}>80$ or $<-80 \mathrm{mV}$ ). These channel events often occurred for tens of minutes and then disappeared. We suspected that certain lipid or solvent (decane) effects might cause such behavior in our recordings from lipid bilayers and will need to use a bSUM to study them (Zheng et al, 2016).

Vesicles of molar PLR 1:10,000 have on average 2 CHGB tetramers per vesicle (assuming $100 \mathrm{~nm}$ diameter). Bilayers were prepared as before (Lee et al, 2013). Fusion of the CHGB vesicles with painted bilayer lipid membranes was induced by slow water flux from trans to cis side. After the appearance of channel activities, salt concentration was balanced. To achieve more reliable fusion of vesicles, $0.5 \mathrm{mM} \mathrm{CaCl}_{2}$ and $1-2 \mathrm{mM} \mathrm{F}^{-}$ions were introduced in the cis side. During the experiments, we eliminated those membranes showing a negative leak current greater than -1.0 pA at $0 \mathrm{mV}$ before salt balancing in the trans side because a small current more positive than -1.0 pA was expected from anion conduction, indicating a tight membrane with little leak. Voltage-clamp mode was used to recording channel activities.

An Axopatch 200B amplifier interfaced with a Windows PC through a DigiData 1322A analogue-to-digital converter was used for recordings. The Axoclamp software (Axon Instrument from Molecular Devices, Inc.) controlled experimental protocols. Clampfit (Axon Instrument) was used to measure currents and single channel events and further data analysis was performed in IGOR Pro (WaveMetrics, Inc.). Current recordings were filtered at $1.0 \mathrm{kHz}$ using a Bessel filter and sampled at $2-5 \mathrm{kHz}$. The liquid junction potential between the solutions we used was $<0.1 \mathrm{mV}$. With balanced salt solutions and under $0 \mathrm{mV}$ holding potential, the recording system had a -0.8 to $-1.0 \mathrm{pA}$ leak current across a thinned membrane in the absence of any channels. This small negative current was corrected when reversal potential was read out from fitting the I-V curves.
For the recordings made from bilayers under asymmetric $\mathrm{Cl}^{-}$and symmetric $\mathrm{K}^{+}$, the cis side had $1.5 \mathrm{mM} \mathrm{KCl}, 150 \mathrm{mM}$ K-isethionate, $10 \mathrm{mM}$ MES-HCl, pH 5.5. The trans side started with $15 \mathrm{mM} \mathrm{KCl}$ and $10 \mathrm{mM}$ MES, $\mathrm{pH}$ 5.5, and was balanced with $135 \mathrm{mM} \mathrm{K}$-isethionate after the appearance of channel activities. The liquid junction potential between these two solutions was measured to be close to zero. In these solutions, we recorded no significant outward currents.

We also tested the patching of blebbed membranes fused from reconstituted vesicles without much success. Recordings from giant unilamellar vesicles need a completely different setup, and will be tested in the future for a separate publication.

\section{Measurement of chloride efflux by an $\mathrm{Ag} / \mathrm{AgCl}$ electrode}

Direct $\mathrm{Cl}^{-}$efflux from vesicles was measured as described previously (Stockbridge et al, 2013). CHGB liposomes of 1:2,000 PLR (equivalent to $\sim 10$ CHGB tetramers per 100-nm vesicle) were loaded with $300 \mathrm{mM} \mathrm{KCl}$ and extruded through a 400-nm membrane filter and passed through a $1.5-\mathrm{ml}$ G-50 Sephadex desalting column in a buffer containing $300 \mathrm{~K}$-isethionate, $25 \mathrm{mM}$ Hepes, pH 7.4, $1.0 \mathrm{mM}$ EDTA, $2.0 \mathrm{mM} \beta-\mathrm{ME}, 0.2 \mathrm{mM} \mathrm{KCl}$. Vesicles $(\sim 100 \mu \mathrm{l}$; inside $\mathrm{KCl}$ and outside $\mathrm{K}$-isethionate) were added to the $1.0-\mathrm{ml}$ recording chamber. The ground $\mathrm{Ag} / \mathrm{AgCl}$ was connected to the recording chamber through a salt bridge. The recording $\mathrm{Ag} / \mathrm{AgCl}$ electrode was directly immersed into the recording solution. $\sim 0.2 \mathrm{mM} \mathrm{KCl}$ was added to the recording solution to stabilize the baseline. DMSO was added as control before valinomycin in DMSO stock was introduced at $0.25-1.0 \mu \mathrm{M}$ to trigger the efflux of $\mathrm{Cl}^{-}$. A stirring bar was used to mix valinomycin with vesicles well. Currents were recorded in the whole-cell mode under $V_{m}=0 \mathrm{mV}$ and at the lowest gain. The data were filtered at $200 \mathrm{~Hz}$ and sampled at 2 $\mathrm{kHz}$. Gap-free recordings were made for 45-60 s. At the end of the experiments, $50 \mathrm{mM} \beta$-octylglucoside $(\beta-\mathrm{OG})$ was added to release all chloride.

\section{Measurement of chloride efflux from vesicles by the light scattering assay}

For steady-state fluorimetry, we followed closely what was described previously (Stockbridge et al, 2013). Vesicles were loaded with $300-450 \mathrm{mM} \mathrm{KCl}$ and $20 \mathrm{mM}$ Hepes at pH 7.4 and were extruded 20 times across a 400-nm membrane filter (Avanti Polar Lipids) before being desalted into a buffer containing $300 \mathrm{mM}$ potassium isethionate. Liposomes were diluted to $\sim 0.50 \mathrm{mg} / \mathrm{ml}$ lipids into $1.0 \mathrm{ml}$ desalting buffer in a stirred cuvette. $1.0 \mu \mathrm{M}$ valinomycin from $1.0 \mathrm{mM}$ stock solution was added and mixed ( 10-15 s) to start the flux. After $\sim 30 \mathrm{~s}$, light scattering was measured at $600 \mathrm{~nm}$ inside a Horiba fluoroLog spectrophotometer (HORIBA Scientific Inc.) using a Fluorlog-2 module at UT Southwestern (Jin et al, 1999; Stockbridge et al, 2013). This assay is called the light-scatteringbased flux assay. At University of Florida (UF), it was repeated using a Fluoromax-4. Data analysis was performed in Origin.

To test the ion selectivity, $\mathrm{CHGB}$ proteoliposomes were prepared with different salts (e.g., $\mathrm{KCl}, \mathrm{KBr}$, $\mathrm{Kl}$, etc.). The proteoliposomes were extruded and desalted in the $\mathrm{K}$-isethionate buffer and used to test the ion flux as described above. 
To titrate the channels per vesicle, molar PLR varied from 1: 100,000 to 1:1,000. Signals from three independent experiments (different batches of vesicles) were averaged and normalized against the maximal signals. Data were fitted with a Hill-equation as follows:

$$
\Theta=\Theta_{\max } /\left(1+\left(k_{D} /[\text { CHGB }]\right)^{\mathrm{n}}\right)+C
$$

The estimated Hill coefficient, $n$, for the steady-state measurement is $\sim 1.4$, suggesting that a functional channel needs more than one CHGB subunits. The steady-state measurement suffers from uneven mixing of valinomycin with vesicles because of uneven partitioning at the starting point and the slower water diffusion during the relaxation step after a change in vesicle shape.

\section{Preparation of bacterial EriC transporter}

The expression construct was obtained from Dr. Christopher Miller at Brandeis University. The protein expression and purification followed a published procedure (Maduke et al, 1999). EriC protein was purified using Ni-NTA affinity chromatography and size-exclusion chromatography in a Superdex 200 column (GE Healthcare). Protein concentration was measured. Proteins were reconstituted in egg $P C$ in the same way as described above for CHGB reconstitution.

\section{A stopped-flow system to observe the fast kinetics of anion flux}

To overcome the shortcomings of the steady-state experiments, we modified the light-scattering based flux assay and used a stopped flow system to achieve quick mixing of equal volumes of valinomycin solution and vesicle solution. An Applied Photophysics SX20 MV stopped-flow spectrophotometer (dead time $~ 2 \mathrm{~ms}$ ) in Dr. Linda Bloom's lab was used. It has an observation cell length of $1.6 \mathrm{~cm}$ and a mixing chamber of $110 \mu \mathrm{l}$. Right before each experiment, vesicles loaded with $300 \mathrm{mM} \mathrm{KCl}$ were exchanged into a buffer containing $300 \mathrm{mM} \mathrm{K}$-isethionate and $10 \mathrm{mM}$ Hepes, pH 7.4 and then loaded into one of the injection syringes. The other injection syringe contained $2.0 \mu \mathrm{M}$ valinomycin in the same buffer. All visible air bubbles were carefully removed. Injection of $55 \mu \mathrm{l}$ of solutions from both syringes started the experiments. The reactions were performed at $20^{\circ} \mathrm{C}$ with a water-bath controlling the temperature of the monitoring cell. Even mixing was achieved within $2 \mathrm{~ms}$. The final mixed solution had $1.0 \mu \mathrm{M}$ valinomycin, $\sim 0.4 \mathrm{mg} / \mathrm{ml}$ lipids (egg PC), and a varying amount of $\mathrm{CHGB}$ protein (PLR). After mixing, light scattering at $610 \mathrm{~nm}$ was monitored. Each data point was the average of three consecutive scans, and each experiment was repeated three times using $\mathrm{CHGB}$ protein from different batches of purification and reconstitution. Titration of PLRs was performed in a continuous run on the same day to prevent system variation. Because of slow decay phase after the initial jump, we focused on the first $40 \mathrm{~ms}$ in our analysis. To titrate valinomycin, $\mathrm{CHGB}$ vesicles of $P L R=1: 2,500$ was used at varying concentrations of valinomycin. Fitting with a Hill-equation yielded a Hill coefficient of $\sim 2.6$, suggesting strong cooperativity for valinomycin in transporting $\mathrm{K}^{+}$ions to support the fast flow of $\mathrm{Cl}^{-}$ions through CHGB. The IC50 $=650 \mathrm{nM}$, which is approximately 130 valinomycin in each $100-n m$ vesicle.
Negative-stain electron microscopy (EM) of reconstituted CHGB vesicles

Copper grids coated with a thin layer of carbon film were baked at $70^{\circ} \mathrm{C}$ overnight the day before experiments. After glow discharge of the grid, $3 \mu \mathrm{l}$ of reconstituted CHGB vesicles with specific PLRs were loaded. The sample was incubated on the carbon-coated grid at RT for $30 \mathrm{~s}$ before being blotted. After that, the grid was stained with $2.0 \%$ phosphotungstic acid (PTA), pH $\sim 8.0$ for $30 \mathrm{~s}$. The grid was blotted and air-dried before being observed in a JEOL JEM2200FS microscope. Images were taken with a Gatan K2 Direct Electron Detector at 25,000× with a defocus level of $-2.0 \mu \mathrm{m}$ and a calibrated pixel size of $1.92 \AA$.

For 3D reconstruction from negative-stain EM images, images were recorded with an electron dose of $20 \mathrm{e}^{-} / \AA^{2}$ on a $4 \mathrm{~K} \times 4 \mathrm{~K}$ Gatan K2 Summit Direct Electron Detector (Gatan) in a counting mode. 180 images were selected based on the power spectra determined by CTFFIND3 (Mindell \& Grigorieff, 2003). 140 images with minimal astigmatism were selected for particle picking. The particles were selected using the Boxer module in EMAN 2 (Tang et al, 2007). A total of $\sim 5,400$ particle images were manually selected. An initial model was generated by angular reconstitution in IMAGIC 5 (van Heel et al, 1996) and finally refined in SPIDER (Frank et al, 1996; Jiang et al, 2004). The final map was calculated from 3,000 particle images at a nominal resolution of $30 \AA$. The handedness of the map was tested with paired images taken from the same specimens at both +15 and $-15^{\circ}$ as what was carried out for the C3PO negative stain map (Llaguno et al, 2014). The small, compact size of the CHGB dimer made us less confident in the handedness at this point. A high-resolution map will be needed to further examine chirality.

\section{CryoEM study of CHGB dimers in detergents}

Quantifoil R2/2 grids (Quantifoil Micro Tools $\mathrm{GmbH}$ ) were coated with a thin carbon film $(\sim 2-3 \mathrm{~nm})$. The ChemiC (Ni-NTA) grids were prepared as described before (Llaguno et al, 2014). 3.0 $\mu \mathrm{l}$ of purified CHGB in detergents was loaded. After incubation for $15 \mathrm{~min}$ in a wet-chamber of $>90 \%$ humidity, the grid was blotted inside a Vitrobot and plunge-frozen into liquid ethane bathed in liquid nitrogen (FEI). After screening in a JOEL2200, good specimens were imaged at HHMI Janelia Farm Research Campus. A Titan Krios microscope equipped with a $4 \mathrm{~K} \times 4 \mathrm{~K}$ Falcon 2 Director (no movie function at the time) was used. The scope was operated at $300 \mathrm{kV}$ and was equipped with a Cs corrector. Automatic data collection was run by a proprietary software package, EPU (FEI). Images were taken under a defocus within a range of -2.5 to $-4.0 \mu \mathrm{m}$ at a magnification of $37,000 \times$, which gave rise to a calibrated pixel size of $1.89 \AA$ at the specimen level.

Because the CHGB dimers were quite small, we scanned many areas for good recognition of the particles. Only a small dataset was successfully built, which came from $\sim 300$ of $4 \mathrm{~K} \times 4 \mathrm{~K}$ images. These images all displayed good Thon rings to a resolution of $\sim 6.0 \AA$ with minimal astigmatism and defocus values ranging from -1.0 to $-4.0 \mu \mathrm{m}$, and showed visible particles. 24,086 particles were picked manually and extracted in $196 \times 196 \AA^{2}$ boxes. The low-resolution negative-stain map was used as the reference for $3 D$ refinement. Five rounds of 2D classification into 50 distinct classes were performed with the program RELION 1.3 (Scheres, 2012). The classes with 
well-defined particles were selected. 3D classification was performed with these selected particles into five classes. Two classes showing higher resolution features were selected for further refinement. The 12,123 particles that were assigned to these two classes were subjected to five additional rounds of refinement using a high-resolution frequency limit of $6 \AA$. A soft mask was introduced to redo the 3D classification and remove $\sim 45 \%$ of the particles. The final map was calculated from $\sim 6,900$ particles and the estimated resolution was $9.8 \AA$ by using a threshold of 0.143 to the gold-standard Fourier shell correlation (Rosenthal \& Henderson, 2003; van Heel \& Schatz, 2005). The map was sharpened by applying a negative $B$-factor of $-75 \AA^{2}$.

\section{Measuring $\mathrm{Ca}^{2+}$ efflux from reconstituted vesicles}

Proteins ( $C H G B$, its mutants, or $I P_{3} R$ ) were reconstituted into vesicles in a PLR of $~ 1: 5,000$ in a buffer made of $20 \mathrm{mM}$ Hepes, $\mathrm{pH}$ 7.5, $100 \mathrm{mM} \mathrm{NaCl}, 1.0 \mathrm{mM}$ EDTA, and $2.0 \mathrm{mM} \beta$-ME (high $\mathrm{pH}$ ) or a buffer made of $20 \mathrm{mM}$ MES, pH 5.5 (low pH). To load $\mathrm{CaCl}_{2}, 1.0 \mathrm{mM}$ $\mathrm{CaCl}_{2}$ was added to the buffer. Right before each experiment, freshly prepared lipid vesicles $(10 \mathrm{mg} / \mathrm{ml}$ ) was extruded 20 times through a membrane filter with an average pore size of $100 \mathrm{~nm}$ (Avanti polar lipids). A PD-10 desalting column (Sigma-Aldrich) was used to change the vesicles into a buffer containing $100 \mathrm{mM} \mathrm{NaCl}$ and 20 mM Hepes, pH 7.4, 1.0 mM EDTA and 2.0 mM $\beta$-ME. Chelex 100 was used to treat the buffers to remove residual calcium ions. Vesicles coming out of the column ( $3.0 \mathrm{mg} / \mathrm{ml}$ lipids) were diluted to $0.2 \mathrm{mg} /$ $\mathrm{ml}$ into the external buffer inside a quartz cuvette with constant stirring. $\mathrm{A} \mathrm{Ca}^{2+}$-sensitive fluorophore, Indo-1, was added to $1.0 \mu \mathrm{M}$. The efflux, if any, was initiated by adding $0.5 \mu \mathrm{M}$ valinomycin. Indo-1 fluorescence at $410 \mathrm{~nm}$ was measured in a Horiba FluoroLog spectrophotometer (HORIBA Scientific Inc.) using the Fluorolog-2 module and an excitation wavelength of $330 \mathrm{~nm}$.

For the $\mathrm{IP}_{3} \mathrm{R}$-containing vesicles, the protein was purified from rat cerebellum as reported before (Jiang et al, 2002), and reconstituted in egg PC in the presence of $2.0 \mathrm{mM} \mathrm{CaCl}_{2}$. The efflux of calcium was initiated by adding $1.0 \mu \mathrm{MIP}$ at different time points. At the end of the experiments, $30 \mathrm{mM} \beta$-OG was added to disrupt the liposomes and release all calcium ions to determine the maximum signal.

\section{Mass spectrometric and Proteomic analysis of proteins}

Trypsinization and mass spectrometry analysis of the protein bands were performed by the Protein and Peptide core facility at UT Southwestern Medical Center. The N-terminal sequencing of the purified fragments eluted from the SDS-PAGE was performed by the same facility. Standard procedures at the core facility were used. After my lab was relocated, the Proteomics core at UF Interdisciplinary Center for Biotechnology Research (ICBR) performed the same services.

The excised bands from the Coomassie-blue-stained SDS-PAGE gels were submitted for identification. The gel bands were destained with $1.0 \mathrm{ml}$ of $50 \mathrm{mM}$ ammonium bicarbonate, $\mathrm{pH}$ 8.0/ acetonitrile (1:1, vol/vol). Each sample was reduced with $40 \mathrm{mM} \mathrm{DTT}$, alkylated with $100 \mathrm{mM}$ of iodoacetamide, and trypsin-digested. Trypsin-digested peptides were desalted with C18-Ziptip (Merck Millipore). A hybrid quadrupole Orbitrap (Q Exactive Plus) MS system (Thermo Fisher Scientific) interfaced with an automated EasynLC 1200 system (Thermo Fisher Scientific) was used. Samples were loaded into an Acclaim Pepmap 100 pre-column $(20 \mathrm{~mm} \times 75 \mu \mathrm{m} ; 3 \mu \mathrm{m}$ C18) and separated in a PepMap RSLC analytical column $(250 \mathrm{~mm} \times$ $75 \mu \mathrm{m} ; 2 \mu \mathrm{m}$-C18) with a flow rate of $250 \mathrm{nl} / \mathrm{min}$ using a linear gradient from solvent A (0.1\% formic acid [vol/vol]) to $25 \%$ solvent B (0.1\% formic acid [vol/vol], 19.9\% water [vol/vol], and $80 \%$ acetonitrile [vol/vol]) for $80 \mathrm{~min}$, and then to $100 \%$ solvent B for additional $15 \mathrm{~min}$.

The candidates were of $97.0 \%$ probability and contained at least 1 identified peptide (Keller, et al, 2002). Protein probabilities were assigned by the Protein Prophet algorithm (Nesvizhskii et al, 2003). Proteins that contained similar peptides and could not be differentiated based on MS/MS analysis alone were grouped to satisfy the principles of parsimony. Proteins sharing identified peptides were grouped into clusters.

Four shared peptides between the two contaminating bands suggest that they are of the same origin. All other candidates only had one peptide detected, very unlikely to be real candidates. Among all the contaminants there is not a single one that can serve as an anion channel.

\section{Ion flow through the CHGB requires a fast-conducting channel, not a slow-acting transporter}

The main difference between a transporter and a channel is the flux rate. Even for the fastest known ion transporter $\left(\mathrm{Cl}^{-} / \mathrm{HCO}_{3}^{-}\right.$transporter), its turnover rate (up to $10^{5}$ per second) would still be a couple of orders of magnitude slower than that $\left(10^{7}\right.$ per second) of a channel. The stopped-flow-based flux assays can provide a good estimate of the flux rate that is limited by the maximum flow through valinomycin molecules. Titration of valinomycin concentration in Fig $6 \mathrm{H}$ suggested that 200 valinomycin molecules per vesicle were needed to generate a significant signal within the 2-ms period of quick mixing. We assume that almost all valinomycin molecules partition to lipid membranes because of their hydrophobicity. Valinomycin shows a turnover rate of $\sim 10^{4}$ per second at $\mathrm{RT}$ in the absence of a transmembrane electrostatic potential. Thus, given the parameters for individual CHGB vesicles (White and King, 1985; Table S3), the estimated $\mathrm{K}^{+}$flux per $100 \mathrm{~nm}$ vesicle is $\sim 2 \times 10^{6}$ per second, or $\sim 4 \times 10^{3}$ in $2 \mathrm{~ms}$, which alone is not enough to release a significant fraction of $\sim 10^{5} \mathrm{~K}^{+}$ions from each $100-\mathrm{nm}$ vesicle without a transmembrane potential.

In the beginning of changing the vesicles from $300 \mathrm{mM} \mathrm{KCl}$ into $300 \mathrm{~K}$-isethionate, initially, the Nernst potential for $\mathrm{Cl}^{-}$was infinitely positive. The mixture had a lipid concentration of $\sim 0.4 \mathrm{mg} / \mathrm{ml}$, a PLR varying from 1:100,000 to 1:1,000 (molar ratio), and $1.0 \mu \mathrm{M}$ valinomycin. After a small leak of $\mathrm{Cl}^{-}$( $W$, the number of ions leaked out) to the outside, an electrostatic potential was established. The Nernst equation was related to the charging of the vesicles to determine the number $W$.

$$
-\frac{R T}{F} \ln \left([\text { vesicles }] \times W /[C l]_{i}\right)=W \times e_{0} / C_{\text {vesicle }}
$$

$R$, gas constant; $T$, temperature; $F$, the Faraday's constant; [vesicles], average concentration of vesicles; $e_{0}$, elementary charge; $C_{\text {vesicle }}$, capacitance of one vesicle of average size $(100 \mathrm{~nm})$.

A numerical solution of $W$ was obtained using MATLAB (Table S3). 
It was noted that the Nernst potential became stable once decreased from the initial infinity. From these estimates, a strong Nernst potential inside would drive the valinomycin transport of $\mathrm{K}^{+}$ ions out. An electrostatic driving force for $\mathrm{K}^{+}$efflux at the first $2 \mathrm{~ms}$ can be expressed as a correction factor, $\exp (z \delta F V / R T)$, which is $\sim 8.9 \times 10^{4}$ at $+295 \mathrm{mV}$, where $\delta$ is a factor for effective conversion of the electrostatic energy into the driving force for ion movement, and is assumed to be unity here under the consideration of no significant energy loss due to either partial charge loss or charge delocalization during the movement of the $\mathrm{K}^{+} /$valinomycin across the bilayer. The correction factor would increase the initial $\mathrm{K}^{+}$flux rate through 200 valinomycin molecule in each vesicle to as high as $\sim 1.8 \times 10^{8}$ per $\mathrm{ms}$ at $+295 \mathrm{mV}$, which is the peak rate. Once the $\mathrm{K}^{+}$ and $\mathrm{Cl}^{-}$ions start to flow out, the correction factor quickly decays when the vesicular potential drops to below $+180 \mathrm{mV}$ (Fig 5H). Such a flux rate would be enough to quickly dump most of the $\sim 10^{5} \mathrm{~K}^{+}$ ions inside each vesicle in $<1 \mathrm{~ms}$, and cause a significant, sudden decrease in osmolality and thus a sudden collapse of the vesicles before water diffusion could follow the shape change of the vesicles. The water movement was found to be in the tens of ms range. This explanation would also account for the sensitivity of the light-scattering signal to [valinomycin]. Moreover, for the fast removal of $\mathrm{KCl}$ from the interior of each vesicle, the efflux of chloride ions had to match that of the potassium ions. A lower limit is $\sim 10^{7-8}$ per second. Possible movement of water molecules accompanying the movement of $\mathrm{Cl}^{-}$only accounts for a tiny fraction of water molecules inside each vesicle.

Our calculation made a testable prediction that a slight increase in $\left[\mathrm{Cl}^{-}\right]$outside of the vesicles would diminish the flux signal by influencing the correction factor. Our data showed that $2-5 \mathrm{mM} \mathrm{KCl}$ in the extravesicular side almost completely abolished the lightscattering signal. It means that when the initial transmembrane Nernst potential drops to $<+150 \mathrm{mV}$ inside $(0.875 \mathrm{mM} \mathrm{KCl}$ outside), the correction factor of $\exp (z \delta F V / R T)$ decreases by $\sim 290$-fold such that the average $\mathrm{KCl}$ efflux rate would become significantly slower than what is needed to generate a sudden drop in osmolality. Our experimental data confirmed this prediction.

Based on the titration of PLRS in CHGB vesicles in the stoppedflow assay, the average number of CHGB subunits per vesicle needs to be at least four per vesicle for generating a fast signal, which is likely equivalent to one channel, and 6-8 CHGB subunits per vesicle are sufficient to reach a maximum signal because of the random Poisson distribution (see the next section). That is, on average, 1-2 CHGB tetramers are sufficient to achieve the fastest efflux estimated. A flux rate of $\sim 10^{5}$ ions per ms per molecule leads to an estimated single-channel conductance of $\sim 100 \mathrm{pS}$ in the presence of $300 \mathrm{mM} \mathrm{KCl}$, close to the measured value.

The fast mixing and even partitioning of valinomycin with the vesicle suspension in the stopped-flow mixing cell and the relatively lipophilic nature of valinomycin makes it possible for us to assume that it takes no free energy for valinomycin to diffuse through the aqueous phase in an estimate velocity of $\sim 1-2 \mu \mathrm{m} / \mathrm{ms}$ via random walk, and become enriched in bilayer membranes. The efflux of a small amount of $\mathrm{K}^{+}$ions carried by valinomycin is followed by the efflux of $\mathrm{Cl}^{-}$ions through the CHGB channels such that the positive potential inside the vesicles would fall quickly from the starting $+295 \mathrm{mV}$, following the exponential curve. The change in potential will slow down the efflux of $\mathrm{K}^{+} / \mathrm{Cl}^{-}$and eventually stop further change in osmolality and vesicle shape.

\section{A Poisson distribution of CHGB subunits among vesicles predicts tetrameric stoichiometry of functional channels}

In the description of the Poisson distribution in the main text, we considered the following assumptions. (1) When $M$ monomers are available in a vesicle and sufficient to join together to form a channel, the assembly is nearly $100 \%$ efficient. Based on the biochemical data, the CHGB protein was fairly stable and our reconstitution was able to incorporate all proteins into vesicles in a preferred orientation; (2) One channel suffices to conduct enough $\mathrm{Cl}^{-}$within 1-2 ms. The conductance of $\mathrm{CHGB}$ with $300 \mathrm{mM} \mathrm{Cl}^{-}$would be >125 pS; (3) With assumption one, all vesicles with less than $M$ copies of $C H G B$ monomers will have no channel and will not contribute to the change in light-scattering. They will form a non functional fraction with a probability of $P(k<M)$; (4) Vesicles with more than $M$ monomers $(N>M)$ will form at least one functional channel (using M subunits), and the surplus monomers ( $N-M$; very likely dimers as the basic units) will not interfere with the function of the assembled channels. With a large number of vesicles for our experiments, the statistical average will likely overcome small experimental variations in vesicle size, completeness in the CHGB insertion into individual vesicles, freedom of CHGB dimers to diffuse and interact with each other in vesicles to form channels, ratios of lipid types in the egg PC mixture, diffusion time for valinomycin molecules to arrive at membranes, and degrees of reaching complete mixing of two equal volumes within the $2 \mathrm{~ms}$ dead time. Therefore, it is relatively reasonable to consider that these assumptions will be satisfied.

Least squares calculation found that the best fit is $M=4$, which is better than $M=5$, but much better than $M=3,6,7$, or 8 . Because of the stability of $\mathrm{CHGB}$ dimers, $M=5$ is not a good solution. The agreement of the predictions from Poisson statistics and the experimental data appears to not be coincidental, especially at the lower range of average $\mathrm{CHGB}$ monomer per vesicle $(\lambda \leq 4)$, where we expect that the assumptions of random distribution and efficient assembly of functional tetrameric channels are well satisfied. Considering the dimers being the dominant species in detergents and the tetrameric form observed in the chemically cross-linked fractions, our data support the tetramers as functional channels, not the pentamers, trimers, or other oligomers.

\section{Supplementary Information}

Supplementary Information is available at https://doi.org/10.26508/lsa. 201800139.

\section{Acknowledgements}

We are grateful to Dr. Barbara Ehrlich (Yale University) for providing the construct for $\mathrm{mCHGB}$, to Dr. Christopher Miller (Brandeis University) for sharing the construct for EriC and the protocols for the chloride flux assays, to Dr. Herbert $Y$ Gaisano (University of Toronto) for the syncollin-pHluorin construct, to Dr. Kuixing Zhang (UC San Diego) for sharing his techniques for releasing granular contents from endocrine cells, to Dr. Sohini Mukherjee and Lora Hooper (UT 
Southwestern Medical Center) for letting us use their FluoroMax-3 system for studying the release of fluorophores from reconstituted vesicles, and to Dr. Sandra Schmid (UT Southwestern Medical Center) for accessing a Horiba fluorometer. We thank Drs. Jose Rizo-Rey, Paul Blount, Peter Michaely, and Lily Huang at UT Southwestern, Frederick Sigworth at Yale University, Drs. Zhonglin Mou and Julie Furlow-Maupin at the University of Florida, and Michael X. Zhu at UT Health Science Center at Houston for critically reading and commenting on the manuscripts, and Dr. Christopher Miller and Dr. Randy Stockbridge for insightful discussions on the flux and bilayer data and the interpretation of the results. We would like to express special gratitude to Drs Jin Koh and Sixue Chen in the Proteomics Core at the Interdisciplinary Center for Biotechnology Research (ICBR) of the University of Florida for technical support in mass spectrometry and proteomic analysis. The work was mainly supported by National Institutes of Health (NIH) (R01GM111367 and R01GM093271 to Q-X Jiang), CysticFibrosis Foundation (JIANG15G0 to Q-X Jiang), Welch Foundation (I-1684 to Q-X Jiang), and Cancer Prevention and Research Institute of Texas(RP120474 to Q-X Jiang), and partially by an American Heart Association National Innovative Award (12IRG9400019 to Q-X Jiang), an National Institute of General Medical Sciences (NIGMS) EUREKA Award (R01GM088745 to Q-X Jiang), and the startup funds from the University of Florida. Some of the experiments reported here were performed in a laboratory constructed with support from NIH grant C06RR30414 with Dr. Jerry Shay as the PI. Data collection of cryoEM specimens was performed at Howard Hughes Medical Institute Janelia Farm Research Campus and at the Florida State University-based "Southeast Consortium for Microscopy of MacroMolecular Machines" supported by an NIGMS grant U24GM116788 (Dr. K Taylor as PI and Q-X Jiang as one of the co-PIs).

\section{Author Contributions}

G Yadav: data curation, formal analysis, investigation, methodology, and writing-original draft, review, and editing.

$\mathrm{H}$ Zheng: data curation, formal analysis, and writing-review and editing.

Q Yang: data curation, methodology, and writing-review and editing. L Douma: data curation, formal analysis, methodology, and writing-review and editing.

LB Bloom: data curation, formal analysis, supervision, and writing-review and editing.

QX Jiang: conceptualization, resources, data curation, software, formal analysis, supervision, funding acquisition, validation, investigation, visualization, methodology, project administration, and writing-original draft, review, and editing.

\section{Conflict of Interest Statement}

The authors declare that they have no conflict of interest

\section{References}

Bartolomucci A, Possenti R, Mahata SK, Fischer-Colbrie R, Loh YP, Salton SR (2011) The extended granin family: Structure, function, and biomedical implications. Endocr Rev 32: 755-797. doi:10.1210/er.2010-0027

Benedum UM, Baeuerle PA, Konecki DS, Frank R, Powell J, Mallet J, Huttner WB (1986) The primary structure of bovine chromogranin A: A representative of a class of acidic secretory proteins common to a variety of peptidergic cells. EMBO J 5: 1495-1502. doi:10.1002/j.14602075.1986.tb04388.x

Benedum UM, Lamouroux A, Konecki DS, Rosa P, Hille A, Baeuerle PA, Frank R, Lottspeich F, Mallet J, Huttner WB (1987) The primary structure of human secretogranin I (chromogranin B): Comparison with chromogranin A reveals homologous terminal domains and a large intervening variable region. EMBO / 6: 1203-1211. doi:10.1002/j.14602075.1987.tb02355.x

Davenport CM, Sevastou IG, Hooper C, Pocock JM (2010) Inhibiting p53 pathways in microglia attenuates microglial-evoked neurotoxicity following exposure to Alzheimer peptides. J Neurochem 112: 552-563. doi:10.1111/j.1471-4159.2009.06485.x

Diaz-Vera J, Camacho M, Machado JD, Dominguez N, Montesinos MS, Hernandez-Fernaud JR, Lujan R, Borges R (2012) Chromogranins A and $B$ are key proteins in amine accumulation, but the catecholamine secretory pathway is conserved without them. FASEB J 26: 430-438. doi:10.1096/fj.11-181941

Diaz-Vera J, Morales YG, Hernandez-Fernaud JR, Camacho M, Montesinos MS, Calegari F, Huttner WB, Borges R, Machado JD (2010) Chromogranin B gene ablation reduces the catecholamine cargo and decelerates exocytosis in chromaffin secretory vesicles. J Neurosci 30: 950-957. doi:10.1523/jneurosci.2894-09.2010

Dominguez RO, Marschoff ER, Gonzalez SE, Repetto MG, Serra JA (2012) Type 2 diabetes and/or its treatment leads to less cognitive impairment in Alzheimer's disease patients. Diabetes Res Clin Pract 98: 68-74. doi:10.1016/j.diabres.2012.05.013

Duran C, Thompson CH, Xiao Q, Hartzell HC (2010) Chloride channels: Often enigmatic, rarely predictable. Annu Rev Physiol 72: 95-121. doi:10.1146/ annurev-physiol-021909-135811

Fahlke C (2001) Ion permeation and selectivity in ClC-type chloride channels. Am J Physiol Ren Physiol 280: F748-F757. doi:10.1152/ajprenal.2001. 280.5.f748

Farquhar MG, Wellings SR (1957) Electron microscopic evidence suggesting secretory granule formation within the Golgi apparatus. J Biophys Biochem Cytol 3: 319-322. doi:10.1083/jcb.3.2.319

Frank J, Radermacher M, Penczek P, Zhu J, Li Y, Ladjadj M, Leith A (1996) SPIDER and WEB: Processing and visualization of images in 3D electron microscopy and related fields. J Struct Biol 116: 190-199. doi:10.1006/ jsbi.1996.0030

Fuchsberger C, Flannick J, Teslovich TM, Mahajan A, Agarwala V, Gaulton KJ, Ma C, Fontanillas P, Moutsianas L, McCarthy DJ, et al (2016) The genetic architecture of type 2 diabetes. Nature 536: 41-47. doi:10.1038/ nature18642

Gliozzi A, Robello M, Fittabile L, Relini A, Gambacorta A (1996) Valinomycin acts as a channel in ultrathin lipid membranes. Biochim Biophys Acta 1283: 1-3. doi:10.1016/0005-2736(96)00101-0

Grimes M, Kelly RB (1992) Intermediates in the constitutive and regulated secretory pathways released in vitro from semi-intact cells. J Cell Biol 117: 539-549. doi:10.1083/jcb.117.3.539

Gros-Louis F, Andersen PM, Dupre N, Urushitani M, Dion P, Souchon F, D'Amour M, Camu W, Meininger V, Bouchard JP, et al (2009) Chromogranin B P413L variant as risk factor and modifier of disease onset for amyotrophic lateral sclerosis. Proc Natl Acad Sci USA 106: 21777-21782. doi:10.1073/pnas.0902174106

Hayner JN, Douma LG, Bloom LB (2014) The interplay of primer-template DNA phosphorylation status and single-stranded DNA binding proteins in directing clamp loaders to the appropriate polarity of DNA. Nucleic Acids Res 42: 10655-10667. doi:10.1093/nar/gku774

Hosaka M, Watanabe T (2010) Secretogranin III: A bridge between core hormone aggregates and the secretory granule membrane. Endocr J 57: 275-286. doi:10.1507/endocrj.k10e-038

Hwang TC, Kirk KL (2013) The CFTR ion channel: Gating, regulation, and anion permeation. Cold Spring Harb Perspect Med 3: a009498. doi:10.1101/ cshperspect.a009498

Jamieson JD, Palade GE (1964) Specific granules in atrial muscle cells. J Cell Biol 23: 151-172. doi:10.1083/jcb.23.1.151 
Jiang QX, Thrower EC, Chester DW, Ehrlich BE, Sigworth FJ (2002) Threedimensional structure of the type 1 inositol 1,4,5-trisphosphate receptor at 24 A resolution. EMBO J 21: 3575-3581. doi:10.1093/emboj/ cdf380

Jiang QX, Wang DN, MacKinnon R (2004) Electron microscopic analysis of KvAP voltage-dependent $\mathrm{K}+$ channels in an open conformation. Nature 430: 806-810. doi:10.1038/nature02735

Jin L, Kulig E, Qian X, Scheithauer BW, Young WF Jr, Davis DH, Seidah NG, Chretien M, Lloyd RV (1999) Distribution and regulation of proconvertases PC1 and PC2 in human pituitary adenomas. Pituitary 1: 187-195. doi:10.1023/a:1009909232243

Johnson RG, Carty S, Scarpa A (1982) A model of biogenic amine accumulation into chromaffin granules and ghosts based on coupling to the electrochemical proton gradient. Fed Proc 41: 2746-2754.

Johnson RG, Scarpa A (1976) Ion permeability of isolated chromaffin granules. J Gen Physiol 68: 601-631. doi:10.1085/jgp.68.6.601

Keller A, Nesvizhskii Al, Kolker E, Aebersold R (2002) Empirical statistical model to estimate the accuracy of peptide identifications made by MS/MS and database search. Anal Chem 74: 5383-5392. doi:10.1021/ac025747h

Laine RO, Morgan BP, Esser AF (1988) Comparison between complement and melittin hemolysis: Anti-melittin antibodies inhibit complement lysis. Biochemistry 27: 5308-5314. doi:10.1021/bi00414a054

Lee S, Zheng H, Shi L, Jiang QX (2013) Reconstitution of a Kv channel into lipid membranes for structural and functional studies. J Vis Exp: e50436. doi:10.3791/50436

Llaguno MC, Xu H, Shi L, Huang N, Zhang H, Liu Q, Jiang QX (2014) Chemically functionalized carbon films for single molecule imaging. I Struct Biol 185: 405-417. doi:10.1016/j.jsb.2014.01.006

Maduke M, Pheasant DJ, Miller C (1999) High-level expression, functional reconstitution, and quaternary structure of a prokaryotic ClC-type chloride channel. J Gen Physiol 114: 713-722. doi:10.1085/jgp.114.5.713

Maduke M, Miller C, Mindell JA (2000) A decade of CLC chloride channels: Structure, mechanism, and many unsettled questions. Annu Rev Biophys Biomol Struct 29: 411-438. doi:10.1146/annurev. biophys.29.1.411

Miki T, Holst O, Hardt WD (2012) The bactericidal activity of the C-type lectin Reglllbeta against gram-negative bacteria involves binding to lipid A. J Biol Chem 287: 34844-34855. doi:10.1074/jbc.m112.399998

Mindell JA, Grigorieff N (2003) Accurate determination of local defocus and specimen tilt in electron microscopy. J Struct Biol 142: 334-347. doi:10.1016/s1047-8477(03)00069-8

Montero-Hadjadje M, Vaingankar S, Elias S, Tostivint H, Mahata SK, Anouar Y (2008) Chromogranins A and B and secretogranin II: Evolutionary and functional aspects. Acta Physiol (Oxf) 192: 309-324. doi:10.1111/j.17481716.2007.01806.x

Mosgaard LD, Heimburg T (2013) Lipid ion channels and the role of proteins. Acc Chem Res 46: 2966-2976. doi:10.1021/ar4000604

Mukherjee S, Zheng H, Derebe MG, Callenberg KM, Partch CL, Rollins D, Propheter DC, Rizo J, Grabe M, Jiang QX, et al (2014) Antibacterial membrane attack by a pore-forming intestinal C-type lectin. Nature 505: 103-107. doi:10.1038/nature12729

Nesvizhskii Al, Keller A, Kolker E, Aebersold R (2003) A statistical model for identifying proteins by tandem mass spectrometry. Anal Chem 75: 4646-4658. doi:10.1021/ac0341261

Obermuller S, Calegari F, King A, Lindqvist A, Lundquist I, Salehi A, Francolini M, Rosa P, Rorsman P, Huttner WB, et al (2010) Defective secretion of islet hormones in chromogranin-B deficient mice. PLoS One 5: e8936. doi:10.1371/journal.pone.0008936

Pedersen SF, Okada Y, Nilius B (2016) Biophysics and physiology of the volume-regulated anion channel (VRAC)/volume-sensitive outwardly rectifying anion channel (VSOR). Pflugers Arch 468: 371-383. doi:10.1007/s00424-015-1781-6
Pimplikar SW, Huttner WB (1992) Chromogranin B (secretogranin I), a secretory protein of the regulated pathway, is also present in a tightly membrane-associated form in PC12 cells. I Biol Chem 267: 4110-4118.

Qu Z, Chien LT, Cui Y, Hartzell HC (2006) The anion-selective pore of the bestrophins, a family of chloride channels associated with retinal degeneration. J Neurosci 26: 5411-5419. doi:10.1523/jneurosci.550005.2006

Ramarao N, Sanchis V (2013) The pore-forming haemolysins of bacillus cereus: A review. Toxins (Basel) 5: 1119-1139. doi:10.3390/toxins5061119

Rizo J, Xu J (2015) The synaptic vesicle release machinery. Annu Rev Biophys 44: 339-367. doi:10.1146/annurev-biophys-060414-034057

Rosenthal PB, Henderson R (2003) Optimal determination of particle orientation, absolute hand, and contrast loss in single-particle electron cryomicroscopy. J Mol Biol 333: 721-745. doi:10.1016/j. jmb.2003.07.013

Rothman JE (1994) Mechanisms of intracellular protein transport. Nature 372: 55-63. doi:10.1038/372055a0

Salama NR, Schekman RW (1995) The role of coat proteins in the biosynthesis of secretory proteins. Curr Opin Cel Biol 7: 536-543. doi:10.1016/09550674(95)80011-5

Scheres SH (2012) A Bayesian view on cryo-EM structure determination. J Mol Biol 415: 406-418. doi:10.1016/j.jmb.2011.11.010

Sreelatha A, Bennett TL, Zheng H, Jiang QX, Orth K, Starai VJ (2013) Vibrio effector protein, VopQ, forms a lysosomal gated channel that disrupts host ion homeostasis and autophagic flux. Proc Natl Acad Sci USA 110: 11559-11564. doi:10.1073/pnas.1307032110

Stockbridge RB, Robertson JL, Kolmakova-Partensky L, Miller C (2013) A family of fluoride-specific ion channels with dual-topology architecture. Elife 2: e01084. doi:10.7554/elife.01084

Takeuchi T, Hosaka M (2008) Sorting mechanism of peptide hormones and biogenesis mechanism of secretory granules by secretogranin III, a cholesterol-binding protein, in endocrine cells. Curr Diabetes Rev 4: 31-38. doi:10.2174/157339908783502406

Tang G, Peng L, Baldwin PR, Mann DS, Jiang W, Rees I, Ludtke SJ (2007) EMAN2: An extensible image processing suite for electron microscopy. J Struct Biol 157: 38-46. doi:10.1016/j.jsb.2006.05.009

Tooze SA (1998) Biogenesis of secretory granules in the trans-Golgi network of neuroendocrine and endocrine cells. Biochim Biophys Acta 1404: 231-244. doi:10.1016/s0167-4889(98)00059-7

van Heel, M., Harauz, G., Orlova, E.V., Schmidt, R. \& Schatz, M. A new generation of the IMAGIC image processing system. J Struct Biol 116(1), 17-24 2837 (1996).

van Heel M, Schatz M (2005) Fourier shell correlation threshold criteria. J Struct Biol 151: 250-262. doi:10.1016/j.jsb.2005.05.009

White SH, King GI (1985) Molecular packing and area compressibility of lipid bilayers. Proc Natl Acad Sci USA 82: 6532-6536. doi:10.1073/ pnas.82.19.6532

Yoo SH (1995a) pH- and $\mathrm{Ca}(2+)$-induced conformational change and aggregation of chromogranin B. Comparison with chromogranin A and implication in secretory vesicle biogenesis. I Biol Chem 270: 12578-12583. doi:10.1074/jbc.270.21.12578

Yoo SH (1995b) Purification and pH-dependent secretory vesicle membrane binding of chromogranin B. Biochemistry 34: 8680-8686. doi:10.1021/ bi00027a017

Yoo SH, Lewis MS (1996) Effects of pH and Ca2+ on heterodimer and heterotetramer formation by chromogranin A and chromogranin $B$. J Biol Chem 271: 17041-17046. doi:10.1074/jbc.271.29.17041

Zhang K, Biswas N, Gayen JR, Miramontes-Gonzalez JP, Hightower CM, Mustapic M, Mahata M, Huang CT, Hook VY, Mahata SK, et al (2014) Chromogranin B: Intra- and extra-cellular mechanisms to regulate 
catecholamine storage and release, in catecholaminergic cells and organisms. J Neurochem 129: 48-59. doi:10.1111/jnc.12527

Zhang K, Rao F, Rana BK, Gayen JR, Calegari F, King A, Rosa P, Huttner WB, Stridsberg M, Mahata $M$, et al (2009) Autonomic function in hypertension; role of genetic variation at the catecholamine storage vesicle protein chromogranin B. Circ Cardiovasc Genet 2: 46-56. doi:10.1161/circgenetics.108.785659

Zheng H, Liu W, Anderson LY, Jiang QX (2011) Lipid-dependent gating of a voltage-gated potassium channel. Nat Commun 2: 250. doi:10.1038/ ncomms 1254
Zheng H, Lee S, Llaguno MC, Jiang QX (2016) bSUM: A bead-supported unilamellar membrane system facilitating unidirectional insertion of membrane proteins into giant vesicles. J Gen Physiol 147: 77-93. doi:10.1085/jgp.201511448

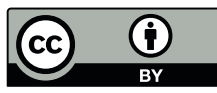

License: This article is available under a Creative Commons License (Attribution 4.0 International, as described at https://creativecommons.org/ licenses/by/4.0/). 